\title{
Virtual Laboratories for Education in Science, Technology, and Engineering: a Review
}

\begin{abstract}
.
Within education, concepts such as distance learning, and open universities, are now becoming more widely used for teaching and learning. However, due to the nature of the subject domain, the teaching of Science, Technology, and Engineering are still relatively behind when using new technological approaches (particularly for online distance learning). The reason for this discrepancy lies in the fact that these fields often require laboratory exercises to provide effective skill acquisition and hands-on experience. Often it is difficult to make these laboratories accessible for online access. Either the real lab needs to be enabled for remote access or it needs to be replicated as a fully software-based virtual lab. We argue for the latter concept since it offers some advantages over remotely controlled real labs, which will be elaborated further in this paper.

We are now seeing new emerging technologies that can overcome some of the potential difficulties in this area. These include: computer graphics, augmented reality, computational dynamics, and virtual worlds. This paper summarizes the state of the art in virtual laboratories and virtual worlds in the fields of science, technology, and engineering. The main research activity in these fields is discussed but special emphasis is put on the field of robotics due to the maturity of this area within the virtual-education community. This is not a coincidence; starting from its widely multidisciplinary character, robotics is a perfect example where all the other fields of engineering and physics can contribute. Thus, the use of virtual labs for other scientific and non-robotic engineering uses can be seen to share many of the same learning processes. This can include supporting the introduction of new concepts as part of learning about science and technology, and introducing more general engineering knowledge, through to supporting more constructive (and collaborative) education and training activities in a more complex engineering topic such as robotics. The objective of this paper is to outline this problem space in more detail and to create a valuable source of information that can help to define the starting position for future research.
\end{abstract}

Key words: virtual laboratory, dynamics based virtual reality, virtual world, distance learning for engineering/STEM education, immersive education

\section{Introduction}

Recently we have seen a number of new ideas appearing in the literature concerned with the future of education and in particular for the teaching of Science, Technology, and Engineering $\left(\mathrm{STE}^{1}\right)$. Some of these notions are novel while others are a re-imagining of existing ideas but in a new context. Technological examples most relevant for this study are: distance learning, elearning, virtual laboratories, virtual reality and virtual worlds, avatars, dynamics-based virtual systems, and the overall new concept of immersive education that integrates many of these ideas together. Many highly reputable institutions ${ }^{2}$ have gathered around this challenging concept, within organizations such as the Immersive Education Initiative (http://immersiveeducation.org) and the Immersive Learning Research Network iLRN (http://www.immersivelrn.org). The mentioned topics and the corresponding technologies can open the way to advanced education in

\footnotetext{
${ }^{1}$ A more widely known acronym is STEM and it includes Mathematics. However, we do not consider Mathematics and hence will use the abbreviation STE.

${ }^{2}$ The Smithsonian Institution, The Massachusetts Institute of Technology (MIT), Harvard University, United States Department of Education, The J. Paul Getty Museum, The University of California Los Angeles (UCLA), Carnegie Mellon University, The Target Corporation, Boston College, Oracle, IBM, The Walt Disney Company, Intel, UNESCO, Bill \& Melinda Gates Foundation, NASA, MIT Media Lab, Stanford University.
} 
STE disciplines. The concept of immersive education has been applied to all aspects of education, including: formal-institutional education, informal massive education, and professional training in companies.

Previously, Internet-based distance education appeared as the first response to challenges resulting from the trend of increased globalization of education (which we now describe as a global competence ${ }^{3}$ ). This trend meant removing all obstacles that limited the access to education, thus making education available to everybody regardless of place, personal disabilities, social status, etc. There have already been significant developments in this direction, with the creation of fully Internet-based universities (http://www.kaplanuniversity.edu; http://www.fernuni-hagen.de/english). However, STE sciences are still far behind in this respect (Potkonjak, Vukobratovic, Jovanovic \& Medenica, 2010), although there have been some notable successes which are worth mentioning such as the development of MOOCs (Massive Open Online Courses) by MIT. MOOCs provide web-based interactive user forums that help build a community for students, professors, and teaching assistants. The increased demand for distance education in technology and engineering subjects has led to new courses being offered using both formal-institutional and informal-massive-online education approaches. Institutions and distance-learning providers are looking to expand the number of online courses that they can offer within the STE disciplines. Less institutional but still considered formal is the provision of professional training in companies. This can include both training that a company provides for its staff, as well as the training that is organized for the staff of customer companies. In these cases virtual laboratories are an economic solution at least for initial and middle-level training. The other aspect is the emergence of the so-called Maker Movement (Honey \& Kanter, 2013; Axup et al., 2014; Sheri, Legaspi, Erenas, Kessler, Gentry, \& Estrada, 2014) where groups of interested people can gather around ad-hoc community projects. A key aspect of this is the need to find qualified participants that can cover all the different problems in the project, regardless of the place where they live. This informal approach to innovation, development, and even manufacturing, requires the use of new approaches and tools to support collaboration, and the online 'co-creation' of new products and technologies. This includes the use of new platforms than can support virtual laboratories and online experiments.

The problems that still constrain the full realization of distance education in STE lie in the fact that these sciences inevitably require laboratory exercises as part of the skill acquisition process. Two different viewpoints to the resolution have appeared. One is to try developing a physical (real) laboratory with distance access, while the other means developing a fully software-based virtual laboratory. We argue for the latter option. The first option, of a remote-access physical laboratory, although possible to create, can be prohibitively complex, especially with regard to the communication and sensory-control hardware and software required, and the overall expense of the equipment and maintenance. Also it is a relatively inefficient solution with poor scalability (only one student can access a particular workplace at a time), and it does not easily support more complex collaborative learning scenarios. The fully software-based virtual laboratory can avoid some of these drawbacks. It has been widely accepted that virtual lab systems and simulators are the desired initial step in STE education and training, while recognizing that more advanced learners will still need hands-on experience with real equipment. However, with the rapid progress in computer graphics, virtual reality, and virtual worlds technologies the boundary

\footnotetext{
${ }^{3} \mathrm{http}: / /$ www.edleader21.com
} 
between what can only be done in the real world and what can be done in the virtual world is reducing.

This paper intends to support wider application of virtual laboratories. The research addresses wider readership - all those involved in development or implementation of e- and distancelearning in STE disciplines, aiming to provide them with relevant information. It approaches the problem from the technological point of view, while the important issues of Learning Theories and Pedagogy will be the focus of a separate publication. The paper first specifies and compares the advantages against the drawbacks of these virtual systems. We then give an overview of the state of the art in virtual laboratories and identify the relevant technologies, and highlight the current trends for future advances in technology and application. In order to make a systematic review and evaluation, we formulate the requirements for a virtual laboratory, which are then used to create the criteria for evaluation (section 3). In Section 4, a critical review of existing virtual laboratories is made based on the adopted criteria. All STE disciplines are considered, with the emphasis on Engineering and in particular on Robotics. This section can be considered as being the heart of this paper. Section 5 presents the current status of virtual-worlds technologies necessary for the creation of a 3D virtual space. Although still rarely used within virtual labs, these technologies are of high interest since the vision of fully integrating virtual labs into virtual worlds is one of the main challenges for future research and development. We then identify the trends for the future advances, which are summarized in Section 6, while Section 7 provides some concluding remarks. The paper ends with a comprehensive list of references.

\section{Advantages and drawbacks of virtual laboratories}

As stated above, our interest is primary in fully software-based virtual laboratories. So, at this point one should specify the advantages of a virtual laboratory over the physical one regardless of whether the latter is used for on-site or remote work. The potential drawbacks and problems arising with virtual labs will also be pointed out.

First about advantages:

- Benefit of savings: virtual systems provide a cost-efficient way for schools and universities to organize high-quality laboratory work in STE disciplines.

- Flexibility: different virtual (simulation) experiments involving different components (virtual apparatus) that can be easily created.

- Multiple access: several students can use the same virtual equipment at the same time.

- Change in the system configuration: it is possible to modify parameters that often cannot be changed in a real system - in a robotic example a user may change the robot links, replace the motors, etc.

- Damage resistance: in a virtual robotic example, collision with the surroundings is allowed; overloading is allowed too - in this case the robot arm will collapse and after the user replaces 
the motors with something stronger, the robot will rise again and continue working. So, "damage" is allowed in virtual world, thus opening the possibility to learn from mistakes.

- Making the "unseen" seen: most real lab devices have a cover to protect from dust, etc; in the majority of cases, the cover cannot be removed, at least not easily. With virtual equipment, covers can simply be removed or made transparent to reveal the inner structure - in a robotic example, this allows the possibility to open the arm and reveal the motors and gearboxes and watch and learn about the rotor, stator, gears, and other transmission components (like belts and spindles).

Now about problems and drawbacks:

- The first problem follows from requests imposed to computer resources. Dynamic modeling and 3D CAD modeling of objects may be rather complex and requiring, especially if objects are integrated in a virtual-world supporting the concept of ambience. General-purpose dynamic models (often called "physics engines", http://en.wikipedia.org/wiki/Physics_engine), like Bullet software (http://github.com/bulletphysics/bullet3), can solve a wide class of systems but are often time-consuming to configure. Dedicated dynamic models based on generalized coordinated and analytical mechanics (Vukobratovic \& Potkonjak, 1982; Vukobratovic \& Potkonjak, 1985; Vukobratovic, Potkonjak, \& Matijevic, 2003) are faster but their problemspecific character can cause problems in situations where a variety of interactions among objects are expected.

- The next drawback comes out from the very nature of a virtual system. The system actually does not exist and hence nothing really bad can come out. This fact sometimes creates a specific student's attitude: lack of seriousness, responsibility, and carefulness - students may feel like they are playing a video game. Let us illustrate this with an example. It is not possible to have an equivalent experience when one looks at a virtual simulation of a machine, compared to standing in front and watching a two-meter-high machine in motion. A similar situation is when a heavy robot carries out a fast manipulation of a 100kg-payload. The real experience immediately makes a student more serious, responsible, and careful.

- Finally, it is a fact (needing no evidence) that the final stage in training usually requires real equipment - the only way to acquire these fine skills is often through actual hands-on experience.

\section{Requirements/criteria}

In order to critically review and evaluate the virtual laboratories, we need to first formulate the evaluation criteria. Our criteria will follow from one crucial requirement (obvious when creating a full virtual replacement of a physical laboratory paradigm), which is: operating a virtual laboratory for a student must feel like they are working with real authentic devices in a real authentic space. Starting from this general requirement, the following four evaluation criteria can be formulated: 
(C1) The user interfaces for each piece of equipment must be identical to the corresponding real devices.

(C2) The behavior of the virtual system (e.g. its state and control variables) must be equivalent to the system behavior in the physical paradigm.

(C3) Visualization must be provided that makes students feel like they are looking at a real authentic thing.

(C4) A 3D laboratory space must be created which allows for communication and collaboration among students and with the lab supervisor (or expert in the field).

Besides these criteria, there are others that could be useful in the context of virtual laboratories . A good example are haptic interfaces. However, the answer to this criterion would be "no" for all considered laboratories. Thus, the criterion would not be appropriate when comparison of virtual labs is done. Future development will probably improve the system performances and augment the list of criteria.

This paper will now discuss the adopted four criteria in more detail, in order to see what enabling technologies are required, and to identify the issues that need further elaboration in this research.

- Developing the user interface $(\mathrm{C} 1)$ is mainly the matter of programming and can be considered as being relatively straightforward. This criterion is of particular importance for laboratories intended for training the system operators. It should be remembered that there may well be copyright issues when copying aspects of the real device (such as the user interface windows) and permission may be needed to do this.

- Realization of criterion (C2) can be seen in two levels (Potkonjak et al., 2010; Potkonjak, Jovanovic, Petrovic, Holland, \& Uhomoibhi, 2013a).

A 'lower level' is concerned with training the system operators (e.g. robot programmers). They will need to learn how to program the system tasks and check whether the system will do what is expected. With a virtual robot (simulator), this will involve examining the robot kinematics and ensuring it executes the programmed motion accurately. This can be considered normal practice for training operators within industry since in reality they will work with a well tuned system, and within the work conditions defined by the manufacturer, and can assume that no unexpected disturbance will occur - under these assumptions, the system/robot will execute accurately what programmed. Such kinematic simulators are available from many robot manufacturers. To avoid the excessive citing of products which are very similar, we will cite just those which, according to authors' opinion, offer something more for education rather than a simple training mode.

In order to support a 'higher level' of education this often means posing questions on how a specific system (e.g. a robot) works and why it works in a particular way. We are often trying to relate causes and consequences, and finally looking for ways to optimize the system. This is important for those students who will experiment with robots, particularly in an unstructured 
environment, and perhaps will even make them from scratch. For this purpose, to achieve fully realistic behavior, we need to model the system dynamics i.e. to use the mathematical model of dynamics to simulate the real-world behavior of the physical system. Thus, dynamics is a crucial criterion since the realistic behavior is a "conditio sine qua non".

Mathematical models for most of the possible lab applications exist but are not always included in virtual labs. The mathematical formulation of system dynamics depends on the field to which the system belongs. In the introduction section we have already distinguished between general-purpose models and dedicated models. However, the question of when to use one or the other approach is still open for discussion.

- Visualization (C3) means that 3D CAD models of all system elements (e.g. all robot parts) are needed and the relation between them has to be defined so that they move synchronously. This requires a focus on 3D CAD modeling. Note that this criterion is particularly relevant for laboratories where physical motion is present (like a robotics lab), while for laboratories where elements do not move (e.g., a lab for electrical circuits) this is often less important.

- The creation of a shared space (C4) requires the utilization of a 3D Virtual World platform, including user avatars (Potkonjak, Jovanovic, Holland, \& Uhomoibhi, 2013b). The use of virtual-worlds has been growing steadily for some time, mainly for the purpose of video games. More recently interest has widened to include new non-leisure applications, provoking the new term - "serious games". Education is among these new applications. Teaching and learning spaces have been developed, which include avatars and text and voice communication. Generally, our research has showed that the available technologies do not easily support system dynamics (dynamics of particular objects and their dynamic interaction). This means that the virtual-worlds platforms are still not ready for the integration of specific physics and dynamics ${ }^{4}$. Further research and development effort is needed to integrate system dynamics within these virtual spaces. This is a rather important issue since the high-quality $3 \mathrm{D}$ ambience is a key enabler for the creation of a full virtual laboratory (Huang, Rauch, \& Liaw, 2010). One should have in mind the increased motivation of students when "playing a sophisticated educational game" (Ibanez, Di Serio, Delgado-Kloos, 2014). Hence, this paper will review the state of the art in virtual-worlds platforms (section 4) in order to show what solutions and environments already exist and how to develop advanced environments and new applications appropriate to robotics and STE virtual laboratories in general (section 5).

\section{State of the art in virtual laboratories}

In the last decade a number of fully software based virtual laboratories in different fields have been developed. In most cases they are specific to an educational context and do not offer possibilities for generalization to a platform applicable to a wider class of engineering disciplines. These laboratories have different levels of technical complexity. For the purpose of this paper we have selected examples which are seen to be relevant to the present state of development and are inline with the identified future trends and which cover different STE applications. The survey starts with two general initiatives and then concentrate on particular

\footnotetext{
${ }^{4}$ The only examples where virtual ambience and dynamics are efficiently integrated are "specific training laboratories" like flight simulators.
} 
results grouped by field of interest. Special attention is paid to Robotics, since it is seen as the best example to demonstrate all of the characteristics of these environments, and the advantages and problems related to virtual laboratories (Jeschke, Hauck, Pfeiffer, \& Richter, 2009).

In order to provide a systematic and concise summary of comparison and evaluation of virtual labs, we have organized the evaluation results into the form of Table 1 . The table gives the relevant data: institution, funding, and an evaluation note according to the proposed criteria described above. After the Table 1, each particular laboratory is further elaborated in more detail.

Table 1. List of virtual lab projects with specifications.

\begin{tabular}{|c|c|c|c|c|c|c|c|}
\hline Project & $\begin{array}{l}\text { Coordinating } \\
\text { Institution }\end{array}$ & Field & C1 & $\mathbf{C 2}$ & C3 & C4 & Funding \\
\hline LiLa & $\begin{array}{l}\text { University of Stuttgart, } \\
\text { Germany }\end{array}$ & $\begin{array}{l}\text { General } \\
\text { initiative }\end{array}$ & - & - & - & - & $\begin{array}{l}\text { European } \\
\text { Commission }\end{array}$ \\
\hline Go-Lab Project & $\begin{array}{l}\text { University of Twente, } \\
\text { Netherlands }\end{array}$ & $\begin{array}{l}\text { General } \\
\text { initiative }\end{array}$ & - & - & - & - & $\begin{array}{l}\text { European } \\
\text { Commission }\end{array}$ \\
\hline VccSSe & $\begin{array}{l}\text { Valahia University of } \\
\text { Targoviste, Romania }\end{array}$ & Physics & yes & yes & no & no & $\begin{array}{l}\text { European } \\
\text { Commission }\end{array}$ \\
\hline TEALsim & $\begin{array}{l}\text { Massachusetts Institute } \\
\text { of Technology, USA }\end{array}$ & Physics & yes & yes & yes & no & $\begin{array}{l}\text { National } \\
\text { Science } \\
\text { Foundation, } \\
\text { Davis } \\
\text { Educational } \\
\text { Foundation }\end{array}$ \\
\hline Ironmaking & $\begin{array}{l}\text { RWTH Aachen } \\
\text { University, Germany }\end{array}$ & $\begin{array}{l}\text { Process } \\
\text { Technology }\end{array}$ & yes & yes & no & no & $\begin{array}{l}\text { University } \\
\text { research }\end{array}$ \\
\hline $\begin{array}{l}\text { The Virtual CVD } \\
\text { Learning Platform }\end{array}$ & $\begin{array}{l}\text { Oregon State University, } \\
\text { USA }\end{array}$ & $\begin{array}{l}\text { Process } \\
\text { Technology }\end{array}$ & yes & no & yes & partly & $\begin{array}{l}\text { University } \\
\text { research }\end{array}$ \\
\hline $\begin{array}{l}\text { Virtual laboratory } \\
\text { of process control }\end{array}$ & $\begin{array}{l}\text { Slovak University of } \\
\text { Technology, Bratislava }\end{array}$ & $\begin{array}{l}\text { Engineering - } \\
\text { non robotic }\end{array}$ & yes & yes & no & no & $\begin{array}{l}\text { University } \\
\text { research }\end{array}$ \\
\hline $\begin{array}{l}\text { Multiplatform } \\
\text { Virtual } \\
\text { Laboratory for } \\
\text { educational } \\
\text { purposes }\end{array}$ & $\begin{array}{l}\text { Universitat Politècnica } \\
\text { de Catalunya, Spain }\end{array}$ & $\begin{array}{l}\text { Engineering - } \\
\text { non robotic }\end{array}$ & yes & yes & no & no & $\begin{array}{l}\text { University } \\
\text { research }\end{array}$ \\
\hline TriLab & $\begin{array}{l}\text { Loughborough } \\
\text { University, UK }\end{array}$ & $\begin{array}{l}\text { Engineering - } \\
\text { non robotic }\end{array}$ & yes & yes & no & no & $\begin{array}{l}\text { University } \\
\text { research }\end{array}$ \\
\hline $\begin{array}{l}\text { Virtual Electric } \\
\text { Machine } \\
\text { Laboratory }\end{array}$ & Firat University, Turkey & $\begin{array}{l}\text { Engineering - } \\
\text { non robotic }\end{array}$ & yes & yes & no & no & $\begin{array}{l}\text { University } \\
\text { research }\end{array}$ \\
\hline $\begin{array}{l}\text { Virtual } \\
\text { Laboratory } \\
\text { Environment }\end{array}$ & $\begin{array}{l}\text { Stevens Institute of } \\
\text { Technology, USA }\end{array}$ & $\begin{array}{l}\text { Engineering - } \\
\text { non robotic }\end{array}$ & yes & yes & yes & yes & $\begin{array}{l}\text { University } \\
\text { research }\end{array}$ \\
\hline RoboUALab & $\begin{array}{l}\text { University of Alicante, } \\
\text { Spain }\end{array}$ & Robotics & yes & yes & yes & partly & $\begin{array}{l}\text { University } \\
\text { research }\end{array}$ \\
\hline $\begin{array}{l}\text { Virtual } \\
\text { Laboratory for } \\
\text { Mobile Robotics }\end{array}$ & $\begin{array}{l}\text { Department of Computer } \\
\text { Science, Tecnológico de } \\
\text { Monterrey, Mexico }\end{array}$ & Robotics & yes & no & yes & no & $\begin{array}{l}\text { University } \\
\text { research }\end{array}$ \\
\hline ROBOMOSP & $\begin{array}{l}\text { Pontificia Javeriana } \\
\text { University, Colombia }\end{array}$ & Robotics & yes & yes & yes & no & $\begin{array}{l}\text { University } \\
\text { research }\end{array}$ \\
\hline VCIMLAB & $\begin{array}{l}\text { Eastern Mediterranean } \\
\text { University, Cyprus }\end{array}$ & Robotics & yes & no & yes & partly & $\begin{array}{l}\text { University } \\
\text { research }\end{array}$ \\
\hline
\end{tabular}




\begin{tabular}{|l|l|l|c|c|c|c|l|}
\hline VirtualRobot & $\begin{array}{l}\text { Polytechnic University } \\
\text { of Valencia, Spain }\end{array}$ & Robotics & yes & yes & yes & partly & $\begin{array}{l}\text { University } \\
\text { research }\end{array}$ \\
\hline VLR & $\begin{array}{l}\text { School of Electrical } \\
\text { Engineering, University } \\
\text { of Belgrade, Serbia }\end{array}$ & Robotics & yes & yes & yes & no & $\begin{array}{l}\text { University } \\
\text { research }\end{array}$ \\
\hline USARSim & $\begin{array}{l}\text { University of Pittsburgh, } \\
\text { USA }\end{array}$ & Robotics & yes & no & yes & yes & $\begin{array}{l}\text { National } \\
\text { Institute of } \\
\text { Standards and } \\
\text { Technology, } \\
\text { USA }\end{array}$ \\
\hline COSIMIR & $\begin{array}{l}\text { University of Dortmund, } \\
\text { Germany }\end{array}$ & Robotics & yes & yes & yes & partly & commercial \\
\hline RoboLogix & $\begin{array}{l}\text { Logic Design Inc., } \\
\text { Canada }\end{array}$ & Robotics & yes & yes & yes & partly & commercial \\
\hline
\end{tabular}

NOTE: There are some important remarks concerning the scores of considered laboratories and their potential applications. One should understand that the relevance of some criterion depends on the foreseen application. Let us illustrate this by an example. Suppose a user is interested in training of robot operators/programmers. In such case, the dynamics of the robot is irrelevant while kinematics, i.e. the robot motion according to the input program, is of major importance. The interfaces that precisely emulate the real systems are also of high relevance. Suppose now that the same lab is used to teach the theory of robotic systems, with the idea that students understand how a robot works. In this case, the interface is mainly irrelevant while the correct dynamic behavior is of prime importance. In order to create a widely applicable and userfriendly laboratory, developers must take care of these facts.

\subsection{General initiatives}

The general initiatives have a wider focus and try to provide a framework for both virtual and remote-access-physical facilities.

"LiLa" is the acronym for the "Library of Labs", an initiative of eight universities and three enterprises, coordinated by University of Stuttgart (Germany) (Richter, Boehringer, \& Jeschke, 2009). The project "LiLa" was co-funded by the European Commission by its eContentplus programme. The goal of the project was to promote the mutual exchange of and access to virtual laboratories (simulation environments), and remote laboratories. LiLa built a portal which provides access to virtual labs and remote experiments. It also includes additional services such as a tutoring system, and 3D-environment for online collaboration.

The Go-Lab Project (Global Online Science Labs for Inquiry Learning at School) was a European collaborative project co-funded by the European Commission (Seventh Framework Programme) (Govaerts, Cao, Vozniuk, Holzer, Garbi Zutin, San Cristóbal Ruiz, et al., 2013; de Jong, Sotiriou, \& Gillet, 2014). It united nineteen organizations from twelve countries, coordinated by the University of Twente (Netherlands). The Go-Lab Project aimed to open up online science laboratories (remote and virtual labs) for large-scale use in education. Go-Lab created an infrastructure (the Go-Lab Portal) to provide access to a set of online labs from worldwide renowned research institutions, such as ESA (European Space Agency, Netherlands), CERN (European Organisation for Nuclear Research, Switzerland), NUCLIO (Núcleo Interactivo de Astronomia, Portugal), etc. These online labs can be used by universities, schools, 
instructors and students, in order to extend regular learning activities with scientific experiments. Experiments can be conducted not only by teachers as a demonstration, but also by students themselves giving them a real experience of scientific work. Go-Lab enables science inquirybased learning and directs students to careers in science.

\subsection{Science-physics}

Project VccSSe (Virtual Community Collaborating Space for Science Education) was a threeyear project started in October 2006, as a collaboration between several institutions from UK, Romania, Spain, Greece, Poland, and Finland. The main purpose of the VccSSe was to adapt, develop, test, implement and disseminate training modules, teaching methodologies and pedagogical strategies based on the use of Virtual Instrumentation in different areas of science (physics, chemistry, biology) in order to benefit students through the availability of virtual instruments in the classroom (Tlaczala, Zaremba, Zagorski, \& Gorghiu, 2009). The virtual instruments combined with dynamic models of physical laws, enabled simulation-based exercises in the virtual laboratory. The system was demonstrated on simple examples such as: Boyle-Mariott's law, Charles's law, Gay-Lussac's law, heat transportation, and DC and AC electrical circuits (including resonance).

The TEALsim, is an open source environment designed for authoring, presenting, and controlling simulations. It was developed by the TEAL (Technology Enabled Active Learning) Project at MIT (Massachusetts Institute of Technology). One of the objectives of TEALsim, is to increase student's conceptual and analytical understanding of the nature and dynamics of electromagnetic phenomena. TEALsim is very useful in electromagnetism, helping students to visualize phenomena. It enables students to see the invisible magnetic field lines, which are not visible in real settings. A single simulation may run as either a Java application or Applet. The "Falling Coil simulation" shows the dynamics of a conducting non-magnetic ring falling on the axis of a fixed magnet. One can vary the resistance of the ring and the strength of the magnetic dipole moment, in order to see how these parameters affect the dynamics of the ring. "Two Point Charge simulation" illustrates the field pattern created by two point charges with opposite signs of charge. In this simulation, the position and charge of each particle can be modified in real time. "Generating Plane Wave Radiation simulation" shows the electromagnetic radiation generated by an oscillating sheet of charge (http://web.mit.edu/viz/soft/visualizations/tealsim; Santos, Guetl, Bailey, \& Harward, 2010).

\subsection{Process technology}

The Virtual Laboratory "Ironmaking" has been developed at the RWTH Aachen University in Germany (Department of Ferrous Metallurgy), aiming to provide a deep understanding of the blast furnace process (Babich \& Mavrommatis, 2009). The blast furnace process represents a nice example of a complex technological process. It is characterized by numerous phenomena (mechanical, hydraulic, physical, chemical and physical-chemical) and reactions, which occur simultaneously and affect each other. The peculiarities of the blast furnace process as a modeling object include: interconditionality; non-linearity of relationships; inertia and transport delays; ambiguity and loss of information (i.e. it is possible to generate two different sets of inputs which both lead to a given set of outputs). The key innovative component of the Virtual Laboratory is 
the VSM (Visual Simulation Model) software that processes parameters entered and outputs both operating and learning results. The VSM software is implemented in Java. Teachers and learners can interact with each other using a software interface that allows monitoring of the activity of the learners; the answering of their questions; and analyzing the results.

The Department of Chemical Engineering at Oregon State University created the Virtual CVD Learning Platform (Figure 1.). It simulates the process of the chemical vapor deposition (CVD). The Virtual CVD Learning Platform provides a capstone experience in which students synthesize engineering science and statistics principles (Koretsky, Amatore, Barnes, \& Kimura, 2008). Simulation of the reactor is based on fundamental principles of mass transfer and chemical reaction, obscured by added disturbance ("noise"). The advanced software features include a 3-D graphical user interface, an instructor Web interface with integrated assessment tools, and a database server. Virtual lab was not intended to be a direct replacement of a physical lab, but rather to complement the physical laboratory in the curriculum so that certain elements (e.g. exercises) can be enhanced. Research showed that students found the virtual laboratory a rather effective learning medium.

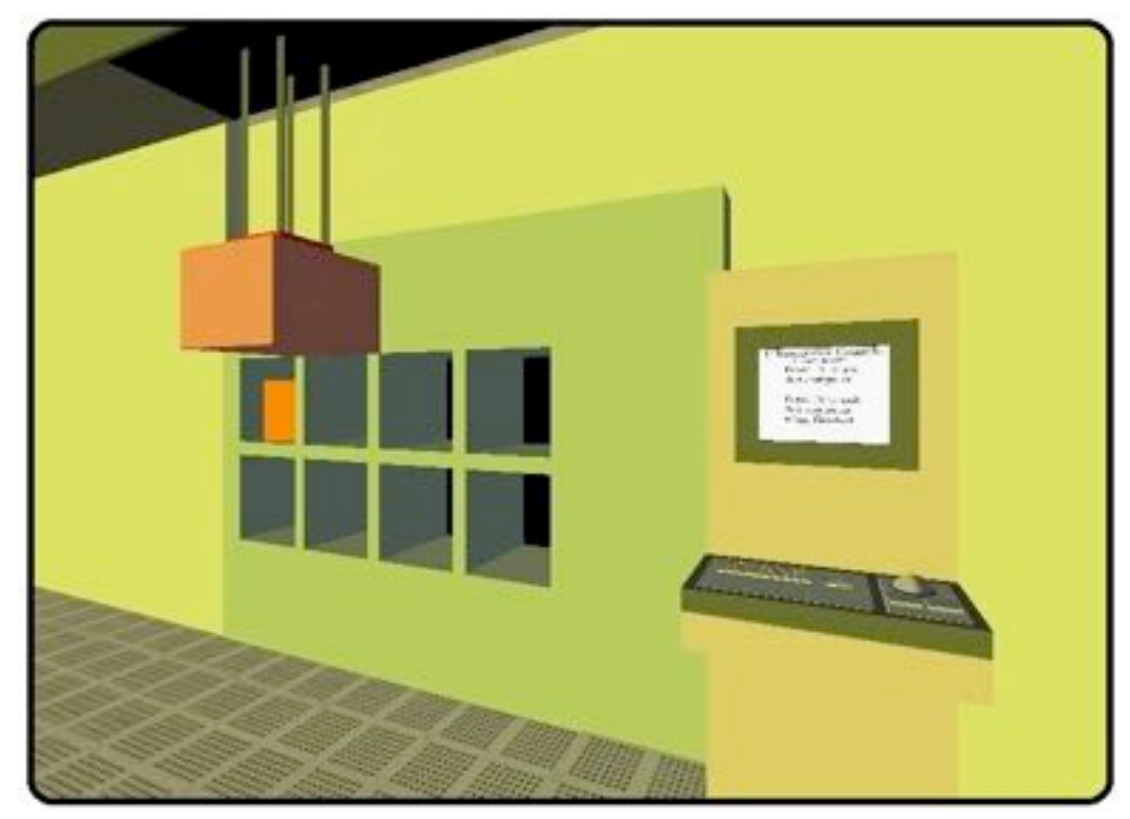

Figure 1. The Virtual CVD Learning Platform (Koretsky et al., 2008). Figure shows loading of wafers into a CVD furnace within $3 D$ graphical user interface.

\subsection{Engineering - non robotic}

A virtual laboratory for control systems applied to technological plants was designed at Slovak University of Technology in Bratislava (Kaluz, Cirka, \& Fikar, 2011). The laboratory provides for virtual simulations of three technological plants (liquid storage tank system, tube heat exchanger, and continuous stirred-tank reactor). For instance, a liquid storage tank system simulates system dynamics, utilizing two general mathematical models of the plant (non-linear and linear). Each of the models consists of several ODEs (Ordinary Differential Equations), depending on the number of tanks in the system. Beside simulations of system dynamics, 
features of process control are also included. The original version of the laboratory was created using the Adobe Flash programming platform, while the later virtual laboratory was based on Java Server Pages.

The concept of a multiplatform virtual laboratory for educational purposes was developed by the Universitat Politècnica de Catalunya, Barcelona, Spain (Signal Theory and Communications Department). This virtual laboratory provides control system experiments at University level. EJS (Easy Java Simulation), a Java language based tool, and Matlab are used for programming. Two sorts of experiments are available from this multiplatform virtual laboratory: magnetic levitator and inverted pendulum-cart system. Magnetic levitation is a very interesting process in control engineering since it is unstable and nonlinear, whereas describing its dynamical behavior, through the analytic model is relatively easy. Experiments in the virtual laboratory emulate real educational equipment, a Magnetic Levitator (MagLev). Therefore, the physical parameters in the virtual model correspond to the real MagLev characteristics. Also, in order to ensure that the behavior of the virtual levitator matches the real one, nonlinear effects have been included in the simulation. Different experiments can be performed and, in all of them, the student can see the levitating ball movements in real-time. The main concepts illustrated by the magnetic-levitator virtual experiment include: PID (Proportional-Integral-Derivative) controllers, root locus controller design, and ITAE (Integral Time Absolute Error) optimal controller design (VillarZafra, Zarza-Sanchez, Lazaro-Villa, \& Fernandez-Canti, 2012).

The TriLab project was developed at Loughborough University, UK. This novel laboratory model combines the three access modes (Hands-On, Virtual, and Remote) in one unifying software package (the TriLab), by using LabVIEW (Abdulwahed \& Nagy, 2013). The focus of our interest is in the virtual mode, which is the Process Control Virtual Laboratory (PCVL). It is used for demonstrating control systems concepts via manipulating a simulated model of a physical process. The PCVL provides a virtual model of an Armfield PCT40 tank filling process, as well as additional control and regulation capacities. The experimental procedures of the lab aim to introduce the students to the principles of control engineering, such as the main components and instruments of a feedback loop, the concept of open-loop control, feedback control, PID (Proportional-Integral-Derivative) control, and PID tuning.

Researchers at Firat University (Turkey) described the creation of a Virtual Electric Machine Laboratory. The virtual platform was designed by using HTML (Hypertext Markup Language), ASP (Active Server Pages) and Borland C++ Builder. The virtual laboratory that was created has the capability of performing experiments in the field of electrical machines. Students are able to immediately see the effect of loading a synchronous motor, such as changes in a supply voltage, or they can make any necessary changes they want. The model for the V/f control and asynchronous drive applications of a synchronous motor was developed with respect to the rotor reference frame. Virtual application can be run for different synchronous motors by changing all motor parameters, such as simulation time (t), sampling frequency (Khz) and voltage (Vf) to be applied to the motor winding. The outputs can be also be visualized graphically (e.g. the velocity of the synchronous motor) (Tanyildizi \& Orhan, 2009).

Stevens Institute of Technology (USA) developed an innovative method for teaching mechanical engineering students about machine dynamics. An online virtual laboratory enables students to 
learn by interacting in a virtual environment (Figure 2.), much like massively multiplayer online games such as Half-life 2, The Sims, WoW (World of Warcraft), and Second Life. The gamebased laboratory environment was created as part of the course "Mechanisms and Machine Dynamics" which introduces the principles of kinematics and dynamics and applies them to linkages, cam systems, gear trains, belt and train drives, couplings, and vibrations. Users (students, teaching assistants, and professors) design their own avatars and discuss projects through instant messaging, all within a virtual 3-D environment of the laboratory. In this virtual environment, the laws of physics are applied. Users are able to manipulate equipment and machinery in order to set up their experiments. Once set up, the experiment yields data based on the interactions of the parts. Progress is monitored by the professor and teaching assistants, and learning is assessed with quizzes before and after the laboratory exercise (Aziz, Esche, \& Chassapis, 2009; Aziz, Chang, Esche, \& Chassapis, 2014).

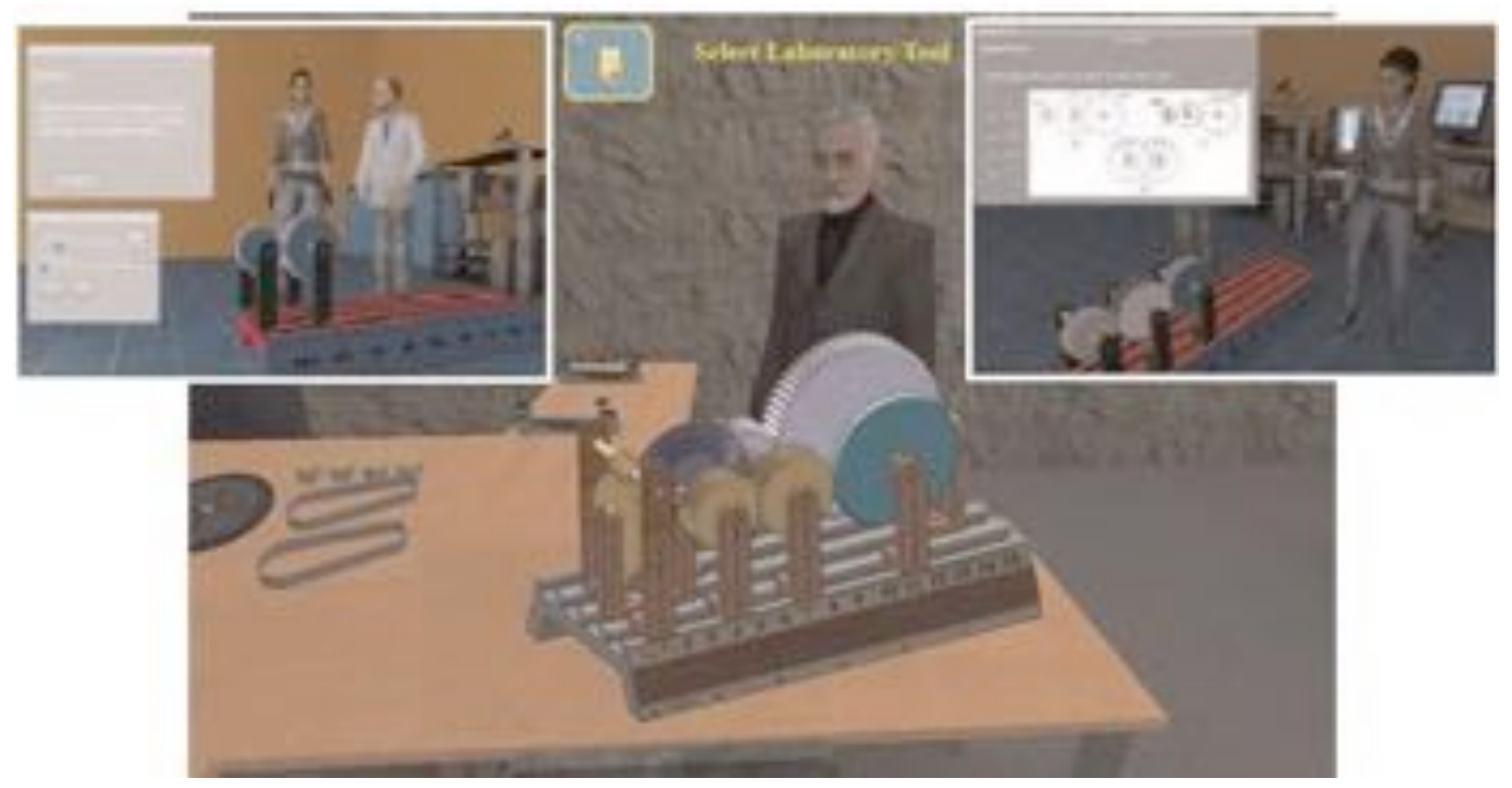

Figure 2. Virtual laboratory at Stevens Institute of Technology (Aziz et al., 2009; Aziz et al., 2014). Good example of the realization of all four criteria defined in Section 3.

\subsection{Engineering - Robotics}

As stated earlier, our primary interest concerns fully-software based virtual laboratories in the field of robotics. Robotics is a complex multidisciplinary area of engineering, which integrates the knowledge of a number of disciplines such as: electrical engineering, mechanical engineering and manufacturing, physics, programming, etc. Hence, robotics is seen as a perfect example to demonstrate the new concepts, potentials and prospects, and the advantages and problems associated with virtual laboratories.

RoboUALab (Figure 3.) is designed as a virtual and remote laboratory to simulate and execute a manipulator robot, and it is developed at the University of Alicante, Spain. RoboUALab is a system that allows students to practice movement commands with a simulated industrial robot. 
Also a real robot, located in a laboratory of the University of Alicante, can be handled by means of tele-operation. This system has been developed since 1999, with several versions having been released since then. The latest version of the applications are based on Easy Java Simulations, an open-source tool for people who do not have advanced programming skills. The user-friendly interface and the graphical simulation are very realistic. With this virtual laboratory, students can learn robotic concepts such as: robot kinematics (using the Denavit-Hartenberg approach), path planning, robot dynamics (affected by link masses, inertias and viscous friction), and programming Java routines for their robot manipulator. In general, the only equipment that the student requires are a computer connected to the Internet, the Java runtime library, and either the VRML software or the Java 3D runtime library, depending on the version of the RoboUALab being used. Advanced RoboUALab features also include a virtual camera enabling users to view a virtual workspace projection of an eye-in-hand virtual camera, and data visualization tools that enable users to view in real-time all the variables concerning the position, transformation, and kinematic and dynamic models of the virtual robot (Torres, Candelas, Puente, Pomares, Gil, \& Ortiz, 2006; Jara, Candelas, Puente, \& Torres, 2011).

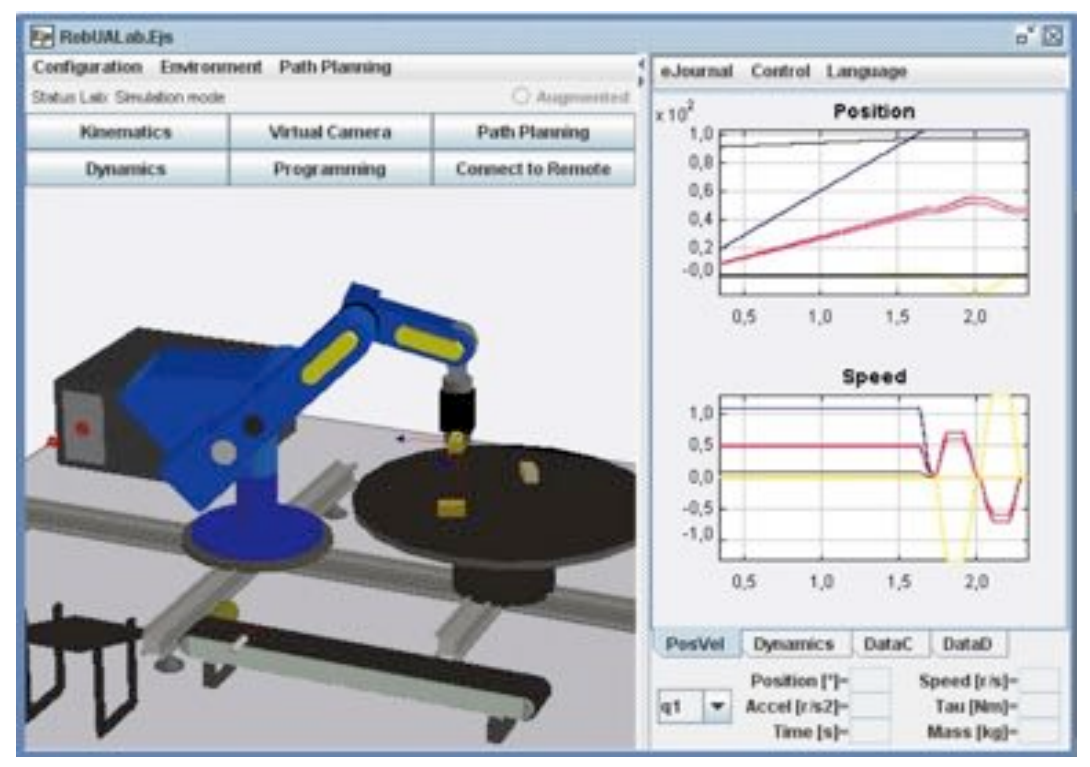

Figure 3. RoboUALab (Torres et al., 2006; Jara et al., 2011). Besides graphical interface, figure shows very important feature of real-time data presentation.

A virtual laboratory for teaching mobile robotics was developed at the Department of Computer Science, Tecnológico de Monterrey (Mexico). The original aim was to develop a novel course for teaching basic robotics at the undergraduate level, with several new didactical and technical contributions (Noguez \& Enrique Sucar, 2006). The virtual laboratory is based on a 3-D simulation, which lets students explore the first concepts in the course: mechanical design, sensors, and control, before they start building a physical robot. An intelligent tutoring system guides the students during their interactions with the virtual lab. The tutoring system is based on a probabilistic relational student model, assessing the effectiveness of the learner exploration behavior. Based on this model, the tutor can decide the best way to guide the student in the experiments. 
ROBOMOSP (ROBOtics MOdeling and Simulation Platform) was developed by the Robotics and Automation Group (GAR) of the Pontificia Javeriana University, in Cali, Colombia. It is a 3D multiplatform, and a CAD system implemented with open-source tools. This modeling and simulation environment for robotic manipulators, adds novel characteristics and functions that are not found in most of the other commercial and noncommercial robotic software packages that are available. It includes a solution to the multibody dynamics problem using an approach based on the automatic calculation of the mass properties of robot multibodies. Furthermore, it includes: embedded engineering analysis tools for dynamic and kinematic simulation and control, a high-level language for off-line programming, a built-in application interface (API) for integrating additional functionality, and a simulation engine capable of remote operation. Also, an important consideration is that it is cross-compatible with Linux, MacOSX, and MS Windows. ROBOMOSP allows users to model: individual physical components or compound elements, full robotic manipulators with user-defined kinematics configurations, discrete and continuous spatial trajectories, multisystem workspaces composed of several robots and other static or dynamic elements (e.g., CNC machines), and complex motion tasks involving the interaction of all components within a specified workspace (Figure 4.). It has been shown that ROBOMOSP works well for training robotic operators, as a research aid, and for studying the mathematical and physical foundations of robotics manipulators, thanks to its ability to permit the expression of models that closely simulate the behavior of real systems within a user-friendly interface (Jaramillo-Botero, Matta-Gomez, Correa-Caicedo, \& Perea-Castro, 2006).

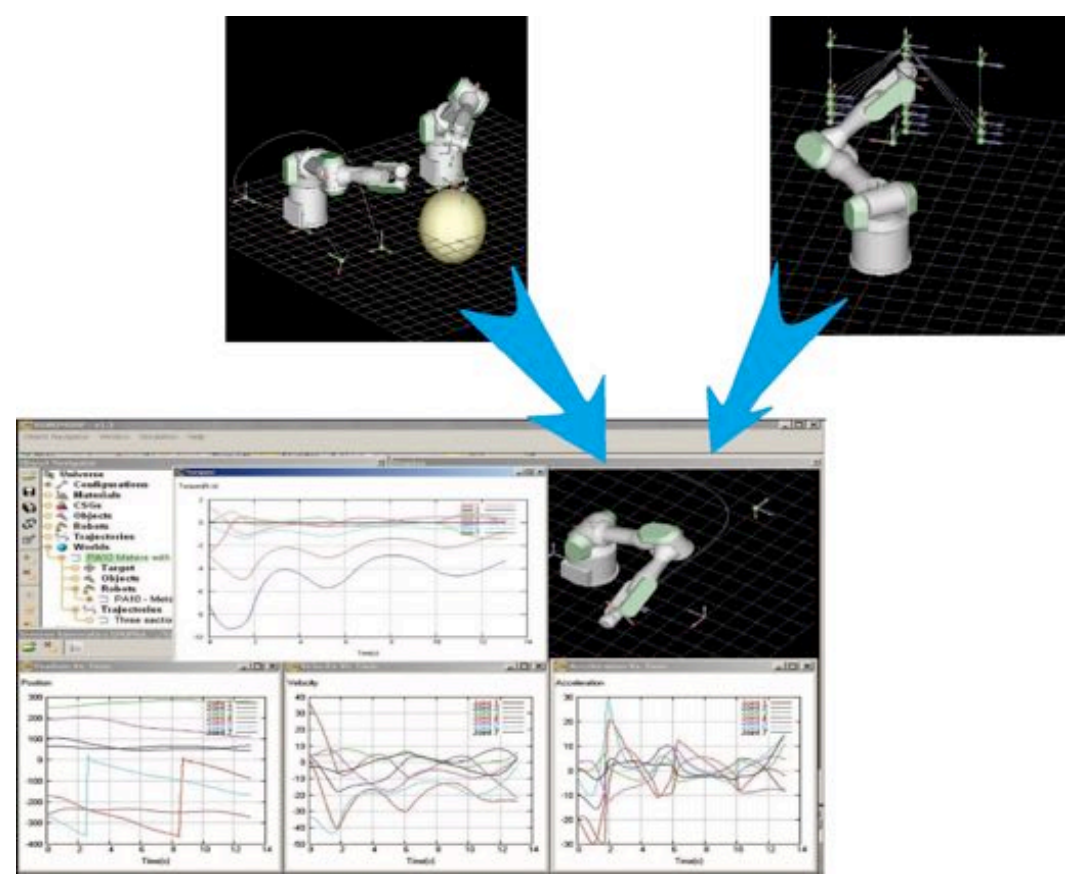

Figure 4. ROBOMOSP (Jaramillo-Botero et al., 2006). Figure shows robotic manipulator executing desired task, as well as appropriate data considering robot kinematics and dynamics.

The VCIMLAB (Virtual CIM Laboratory) was developed at the Eastern Mediterranean University, Cyprus (Hashemipour, Manesh, \& Bal, 2011). It is an educational software application for training users on the operating principles of CIM (computer integrated manufacturing) and automated production systems, which make use of industrial robots, CNC 
machines, and automated assembly equipment. The system provides a 3D interactive, virtual laboratory environment (Figure 5). The virtual laboratory consists of virtual simulation models of common CIM hardware, robots, machines and computer systems. A real layout of a CIM laboratory located at the Eastern Mediterranean University was taken as a reference model for the development of the simulation models. The reference laboratory consists of two flexible manufacturing cells, including programmable robot arms, a CNC milling machine and several pieces of CIM equipment. The virtual simulation environment very closely represents the real laboratory. The students can operate the virtual simulation models, according to the real-time operating principles. The VCIMLAB provides several combinations of laboratory models for a step-by-step approach of learning the CIM systems (starting from the easiest, through to more complex cases). These simulation environments are called 'rooms'. The VCIMLAB provides a total of four rooms.
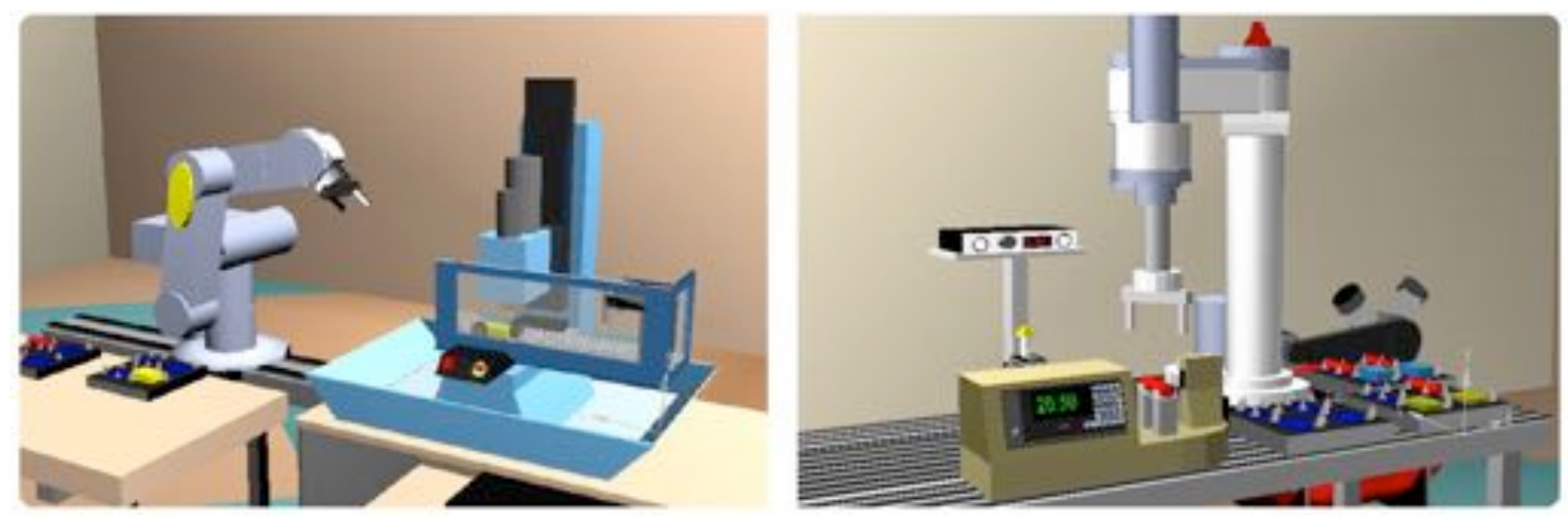

Figure 5. VCIMLAB (Hashemipour et al., 2011). Automated production system presents virtual replica of the real CIM laboratory.

VirtualRobot is a freeware software suite developed in $\mathrm{C}++$, by the DISA-UPV Robotics Group (Valencia, Spain). It is a graphical software application designed to be a general, flexible and open platform for robotics application, research and education. From it's beginning in 1998, it was motivated by the need for a remote graphical application for programming, monitoring and simulating multi-robot cells in the control system GENERIS (Generalised Software Control System for Industrial Robots). It has been shown that VirtualRobot can be a useful tool in many fields of robotics, such as with industrial robots, mobile robot control (wheeled, sub-aquatic and walking robots), collision detection, motion planning, etc. VirtualRobot software (VRS) can simulate not only manipulator-arms, but also multi-axis machines such as conveyors, turntables, machine-tools, sensor systems and mobile robots. Robots can be attached one to one, or many to one, in order to form more complex and redundant devices, such as walking robots. A VRS user interface aims to reduce the time needed for the learning phase, even for new users, supporting educational, research and industrial uses. The capabilities of the VRS make it possible to simulate robots working in dynamic environments (Sapena, Onaindia, Mellado, Correcher, \& Vendrell, 2004).

The Virtual Laboratory for Robotics (VLR) was developed at ETF (School of Electrical Engineering, University of Belgrade, Serbia) (Potkonjak et al., 2010; Potkonjak, Jovanovic, Petrovic, Holland, \& Uhomoibhi, 2013a). The idea behind VLR was to demonstrate the main 
features of industrial robots, being perfect examples of complex mechatronic systems. State-ofthe-art technologies are used in order to realize the VLR concept, through appealing graphical modules, and a modern user interface. The notion of dynamics is of key relevance in the concept. Therefore, mathematical models of the dynamics is at the core of the virtual robot. Current version of VLR enables users to choose one of five industrial robots that represent most common robotic configurations. Available robots are: UMS2, Kuka R850, Kuka KR 1000 Titan, STAUBLI RX270, and ETF configuration. One of the key features is that motors and other parameters can be easily changed. In this way, students can explore robot behavior in the presence of different types of motor and transmission systems, and explore the influence of motor parameters on the system. A choice between control schemes is offered with both classical feedback, or some predefined feedforward blocks provided. All the control parameters can be freely chosen. As well as simply changing the parameters of a predefined PID scheme, students have the possibility to define a "custom block" in the control scheme. By developing this block, users can define their own controller and then check the results. Graphical characteristics of the animation include: detailed robot image, different viewpoints/camera positions (including a camera mounted on the robot gripper), and different lighting. Also, the virtual robot can leave a trace behind it when it moves. Another important feature of the virtual robot is that it's graphical representation includes all the inner mechanisms, such as the transmission systems (gears in a gearbox, belts, rack and pinion, spindles, etc.), the motor elements (stator with magnets, rotor), the encoder inner structure, etc are included. All these inner mechanisms move in complete accordance with the kinematic and dynamic model. Figure 6.(b) shows the drive and transmission mechanisms used to move the elbow of the jointed robot (Figure 6.(a)). All of these advanced features of the user interface highlight the possibility of using the VLR for experiments and exercises aimed not just at training future robot operators, but also for helping students to learn robotic theory. Currently improvements of VLR are being carried on with the aim to integrate virtual worlds into the system (Potkonjak, Jovanovic, Holland, \& Uhomoibhi, 2013b).

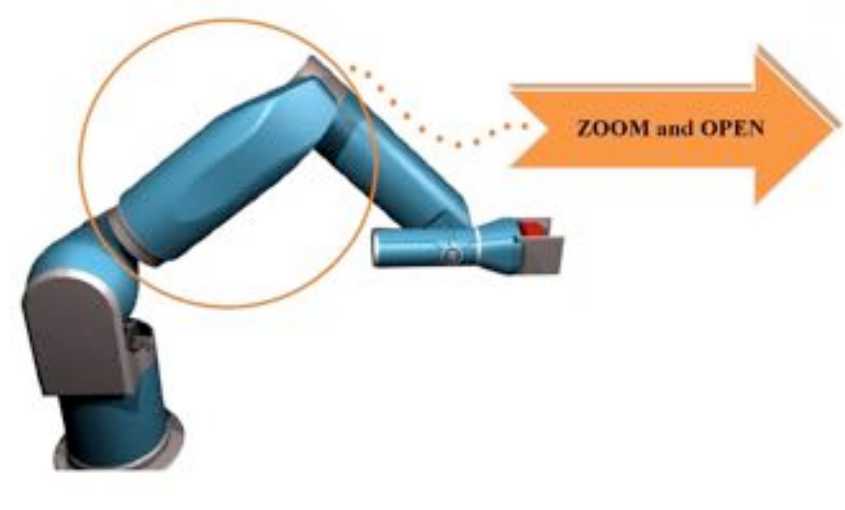

(a)

ETF jointed configuration

(external view of the robot)

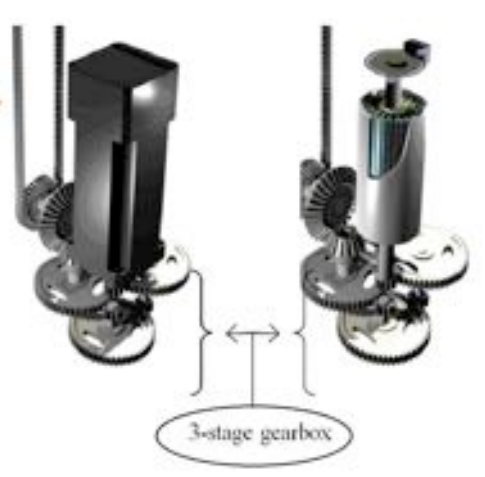

(b)

Reveling the inner structure of the elbow joint drive.

Figure 6. VLR at ETF (Potkonjak et al., 2010; Potkonjak et al., 2013a). Reveling of the inner structure, shown on the right, can be extremely useful for deeper understanding of mechanism principles.

USARSim is an open source high fidelity multi-robot simulator that can be used both for education and research. Development of the simulator started at Carnegie Mellon University and 
the University of Pittsburgh. Although it was originally developed for urban search and rescue simulations, it is a general purpose multi-robot simulator. USARSim is platform independent and runs on Windows, MacOS and Linux. It builds upon the Unreal Engine (Epic Games), a commercially available game engine. USARSim offers a set of characteristics that differentiates it from most available simulators. It is highly extendible and configurable, thus allowing users to easily add new sensors, or even model new robots. USARSim was initially developed with a focus on differential drive wheeled robots. However, the spectrum of available platforms significantly grew, due to increased interest. The currently available version offers: underwater vehicles, legged platforms, humanoids, etc (Carpin, Lewis, Wang, Balakirsky, \& Scrapper, 2007).

In addition to the academic research and effort for developing software for robotics described above, there are also several commercial products available. A brief overview of some of these products is described below.

COSIMIR (Cell Oriented Simulation of Industrial Robots) is a robot emulation software package, developed by the University of Dortmund in Germany. It provides a virtual learning environment in the field of robotics (Figure 7.). Step by step, it is possible to advance independently from very simple robotics applications right through to highly complex work cells in a realistic, simulated 3D work environment. The cells can contain models of Bosch Rexroth, Mitsubishi and Staubli Robots. All movement and handling operations can be simulated to avoid collisions and to optimize the cycle times. The direct download of tested programs and positions into a robot controller is supported. COSIMIR contains libraries of robots, end-effectors, geometric shapes, and mechanisms (e.g. conveyor belts and part feeders). The software also provides the ability to import objects that have been developed with an external CAD package (e.g. AutoCAD, SolidWorks, etc.) (Freund \& Pensky, 2002).

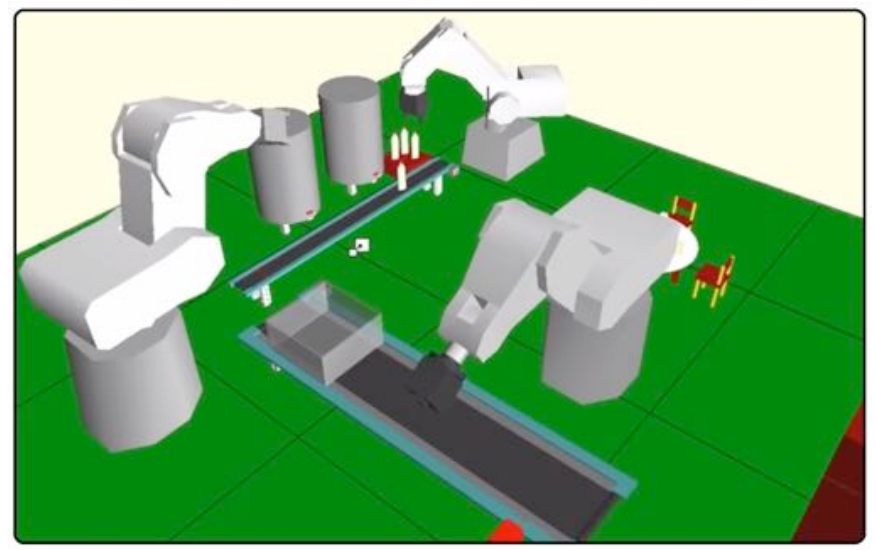

Figure 7. COSIMIR (Freund \& Pensky, 2002). Figure shows cooperation between three robots.

RoboLogix is a "state of the art" robotics simulation software package developed by the Logic Design Inc. (LDI), Canada. It is designed to emulate real-world robotics applications (Figure 8.). RoboLogix introduces a wide range of practical applications through the standard five-axis industrial robot. These applications include pick-and-place, palletizing, welding, painting, and allow for customized environments so that one can design your own robotics application. The 
user can run the simulator to test and visually examine the execution of robot programs and control algorithms. Also plotting of the joint accelerations, velocities and positions is included. The benefits of RoboLogix simulation include: a user-friendly 3D interface; the ability to develop, test, and debug programs in a safe, non-hazardous environment; perform accurate robot simulations to verify reach, cycle time, through-put, etc.; compare robotic programs in order to optimize cycle times; and being able to enter, modify and retrieve programs using a simulated teach pendant (http://www.robologix.com).

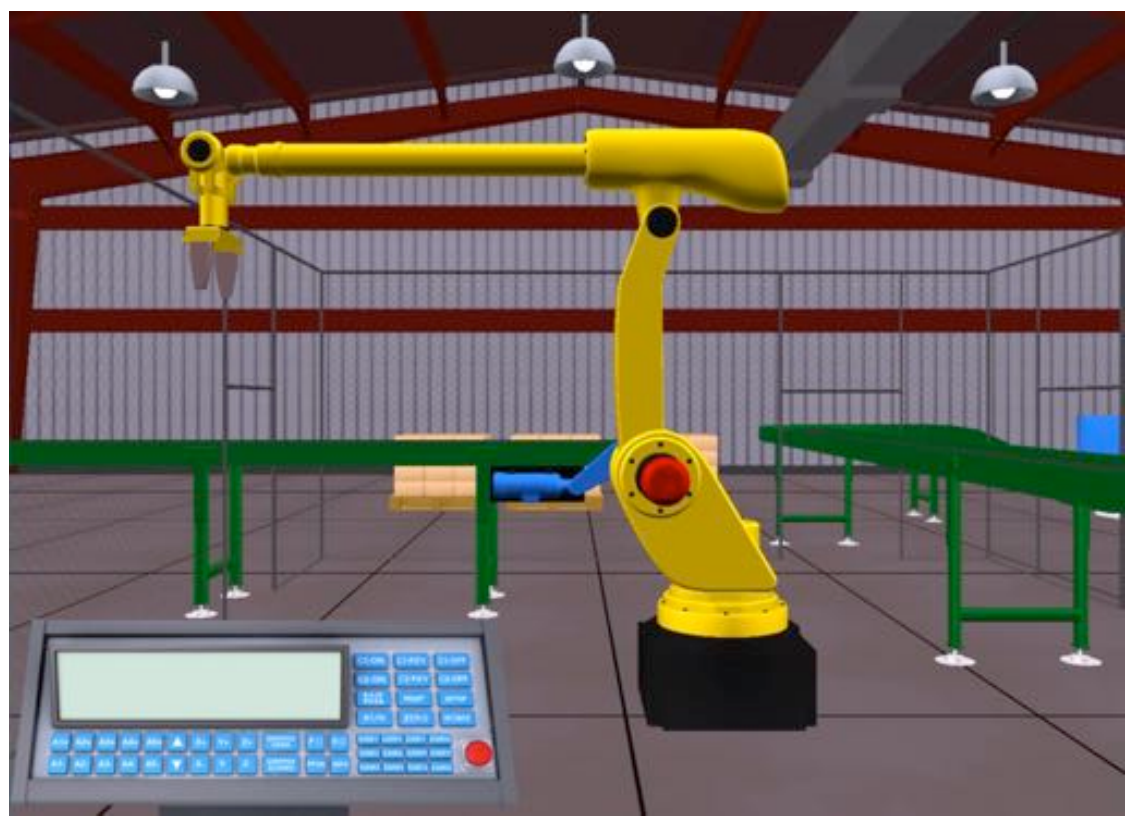

Figure 8. RoboLogix (http://www.robologix.com). Graphical simulation of "real life scenario", robot working in production line.

\section{State of the art in virtual worlds}

Virtual worlds are still rarely used as an integral part of virtual labs, as it can be seen from Table 1. However, they are becoming an important tool in modern education and a missing link in the creation of advanced virtual laboratories. Virtual worlds can create a realistic ambience and provide a platform for realistic communication among users even allowing for "face to face" interaction by means of avatars. Due to their significance, we have dedicated a section to a summary of virtual worlds below.

A few decades ago, virtual reality caused a lot of excitement. Demonstrations were made, showing people wearing goggles for 3D vision and gloves with a sense of touch. However, this kind of virtual reality never found its way into the widespread use (Hut, 2007). This was due to a several reasons: technical difficulties, high costs, and finally it was not convenient to wear all the extra gear. However, a very different form of virtual reality (game-based technology developed for personal computers) has rapidly gained attention of millions of people. Visual environments have developed from the original online games of over 40 years ago (Duncan, Miller, \& Jiang, 2012). 
Today, it could be said that "Virtual Reality (VR) is the use of computer graphics systems in combination with various display and interface devices to provide the effect of immersion in the interactive 3D computer-generated environment" (Pan, Cheok, Yang, Zhu, \& Shi, 2006). Such environments are called virtual environments (VE).

A further development was the three-dimensional multi-user virtual environment (MUVE). Perhaps, the most popular example of such an environment is Second Life (SL), which will be described later in the text. One of the main characteristics of a MUVE is that each user is represented by an animated online persona - an avatar. An avatar can move around the 3D world. Through an avatar, a user can interact with digital objects, and communicate with other users. Users often enter these environments for social reasons, to meet and communicate with other people, or to find some kind of entertainment.

Beside gamers, the use of virtual environments has also attracted considerable academic research. The educational purpose of virtual environments (Dieterle \& Clarke, 2009; Ketelhut, 2007) has become a promising area of research, enriching the methods of teaching and learning. So, a new form of virtual environment with the specific purpose of enabling teaching and learning, is developed - the virtual learning environment (VLE). An important role of the VLE is that it helps in improving the students'/learners' ability of analyzing problems and exploring new concepts (Pan et al., 2006).

Among existing open source and commercial virtual world platforms, we will present those that are currently being most used or are promising for our problem area. So, the following review will be guided by the appropriate features:

- Whether specific virtual environment has been used in education.

- Whether specific virtual environment has the potential to be used for the development of virtual laboratories according to the previously defined criteria (C1-C4).

\subsection{Second Life}

Second Life (SL) is an online virtual environment launched in 2003, developed by Linden Labs. It is a 3D simulation of the real world (Figure 9.), with buildings, islands, oceans, etc. Almost everything that can be found in the real world has its equivalent in the Second Life. Users of the Second Life, called Residents, can interact with each other through avatars. Residents can explore the virtual world, meet and socialize with other Residents, and participate in numerous activities. Second Life also allows users to create content (for example they can even create and trade virtual properties and services with each other) (Kaplan \& Haenlein, 2010). What we see today in the Second Life is mainly created by the users. Second Life has its own currency, the Linden dollar, convertible into the real US dollar. Users can enter SL for free, but if they wish to buy virtual articles, they have to pay real money. So, in many ways, SL functions like a nation, having its own economic and social structure. Since SL was launched, the number of Residents has grown to more than 37 million registered users. The number of signups on a daily basis is between 7000 to 14000 (http://secondlife.com). 
Usage of Second Life varies, from business to social communities. However, our main interest is educational purpose of SL. In the last few years, academic researchers have shown great interest in using virtual environments (especially SL), as a novel platform for e-learning. Consequently, Second Life is used as an education platform by many academic institutions (universities, colleges, libraries...). One could say that Second Life is currently the most mature and popular multi-user virtual world platform being used in education (Warburton, 2009). There are over one hundred regions in SL, used for educational purposes. They cover a number of subjects. Language learning is the most widespread type of education in SL. Many universities and schools use 3D virtual environment to support language learning. Unlike traditional distance learning, SL provides a more personal learning experience, so it is favored by many researchers and lecturers.

Also a number of medical and health education examples from SL have been reported. For example, Ohio University created a "Nutrition Game" (Boulos, Hetherington, \& Wheeler, 2007), where users can learn about the impact of fast food on health. Players are allowed to experiment with various eating styles in simulated fast-food restaurants, with the final goal to make healthy choices that will result in a high score for the game and a positive effect on health. Another interesting example was an interactive genetic laboratory/museum, called the "Gene Pool". It features simulated lab experiments, tutorials and videos. In order to enhance the learning experience visitors can learn, in great detail, about DNA and human chromosomes, and explore a giant 3-D eukaryotic cell, etc. (Boulos et al., 2007; Wiecha, Heyden, Sternthai, \& Merialdi, 2010).

According to some researchers (Barkand \& Kush, 2009), over 300 universities around the world teach courses or conduct research in SL.

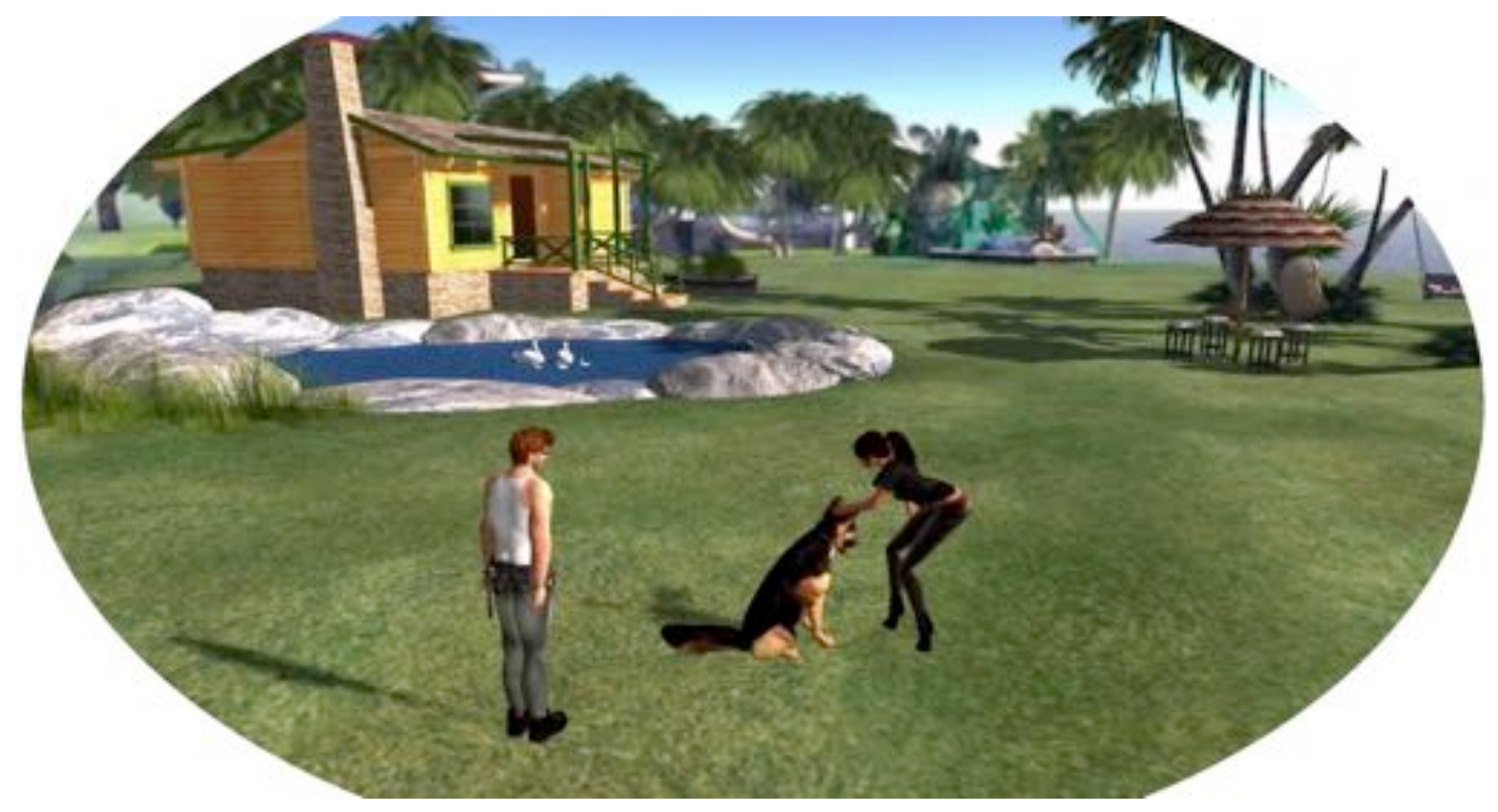

Figure 9. Second Life (http://secondlife.com). Figure shows an example of interaction in virtual environment. 


\subsection{RealXtend}

The development of RealXtend (Figure 10.) began in 2007. It was originally based on the OpenSimulator server code, and used the Second Life viewer. However, realXtend eventually developed its own viewer, and in that way moved away from the other projects. The first enduser version of the Naali, realXtend viewer (substantially different from the SL viewer) was released in early 2010. By the end of the year it completely replaced the earlier version. In that way, through creating of its own viewer, the realXtend developers have freed themselves from the technical and licensing constraints of the SL viewer. RealXtend is programmed mainly using C\# and Python (http://realxtend.org; Davies \& Callaghan, 2010).

Users of realXtend, can interact with each other through very realistic avatars. Also, it is important to say that any 3D modeling application can be used to create content for realXtend (e.g., Blender). So in that way, a complete open source toolkit exists for creating realXtend worlds or applications. RealXtend can be augmented through the addition of Python scripts adding advanced features into the default world. It also offers a library of objects. RealXtend technologies can be used for many kinds of different applications (e.g., knowledge transfer or learning purposes (Mattila, Krajnak, Arhippainen, \& Brauer, 2012)). Inside RealXtend there is a Meshmoon hosting system, which provides the ability to share courses, materials, make groups, environments, and also organize commercial activities (http://realxtend.org; Davies \& Callaghan, 2010).

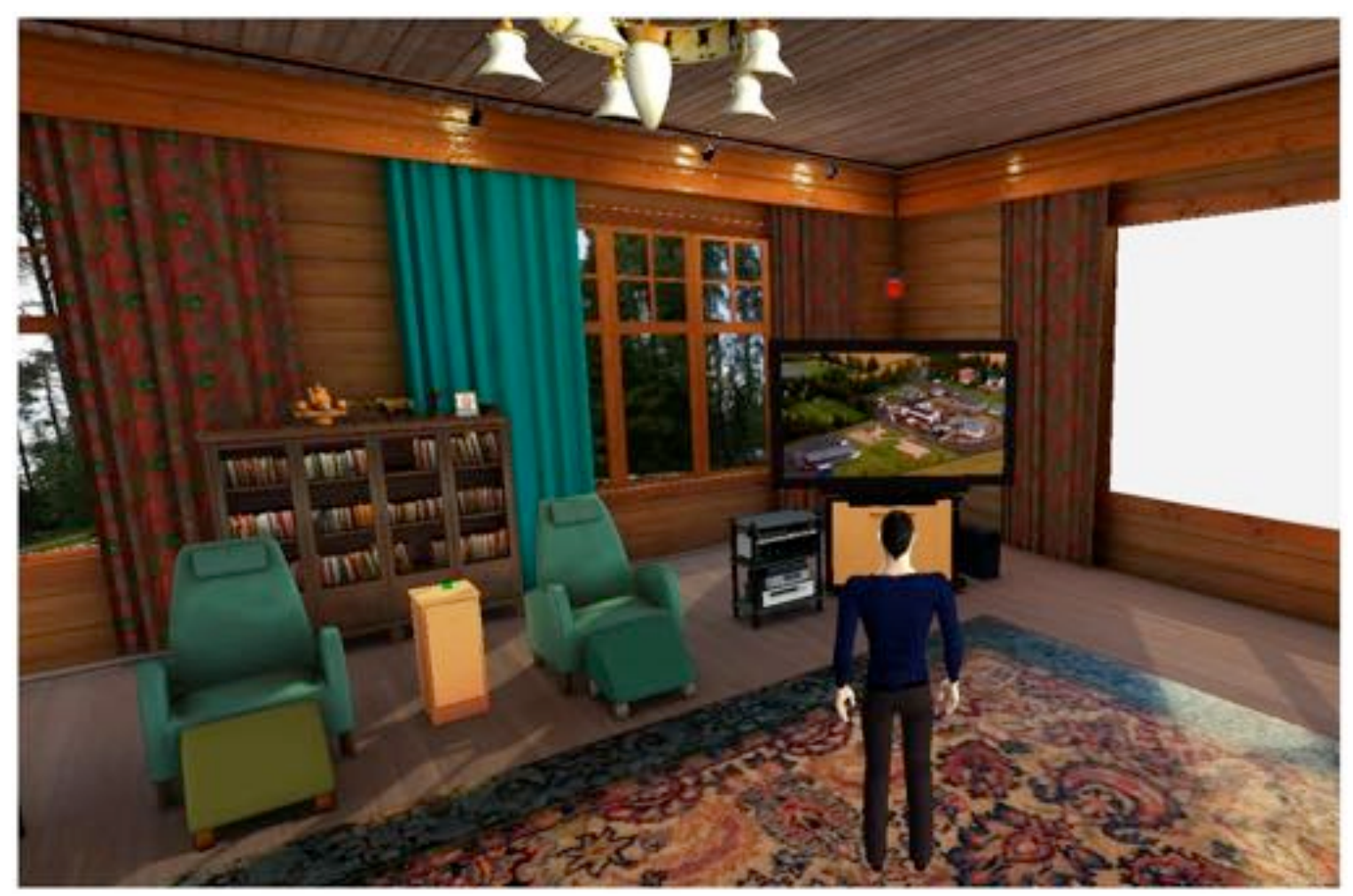

Figure 10. realXtend (http://realxtend.org). Library of object helps to create a rich content, in that way providing the realistic ambience. 


\subsection{OpenSimulator}

OpenSimulator (Figure 11.) is an open-source server platform for hosting virtual worlds, written in $\mathrm{CH}$. It can be easily expanded via plugin modules to build a completely custom configuration. OpenSimulator currently uses the Second Life protocol for client to server communication, and it is compatible with the SL viewer. Also, it is compatible with a range of other virtual world viewers being developed by the open-source community. It supports many programming languages for application development: Linden Scripting Language, C\#, Jscript, VB.NET, etc. (Onyesolu, 2009).

OpenSimulator can operate in standalone or grid mode. In standalone mode, a single process handles the entire simulation. Standalone mode is simpler to configure, but it is limited to a smaller number of users. On the other hand, in grid mode various aspects of the simulation are separated among multiple processes, which can exist on different machines. Grid mode has the potential to scale as the number of users grows (http://opensimulator.org).

Recently, academic researchers have shown great interest in using OpenSimulator for educational purposes (Andreas, Thrasyvoulos, Stavros, \& Andreas, 2010; Allison, Campbell, Davies, Dow, Kennedy, McCaffery, et al. 2012). Nice example is an immersive virtual laboratory for teaching computer networks. It consists of test benches with computers, racks with routes, etc. Also, virtual tutor is present in the form of avatar (Voss, Nunes, Muhlbeier, \& Medina, 2013).

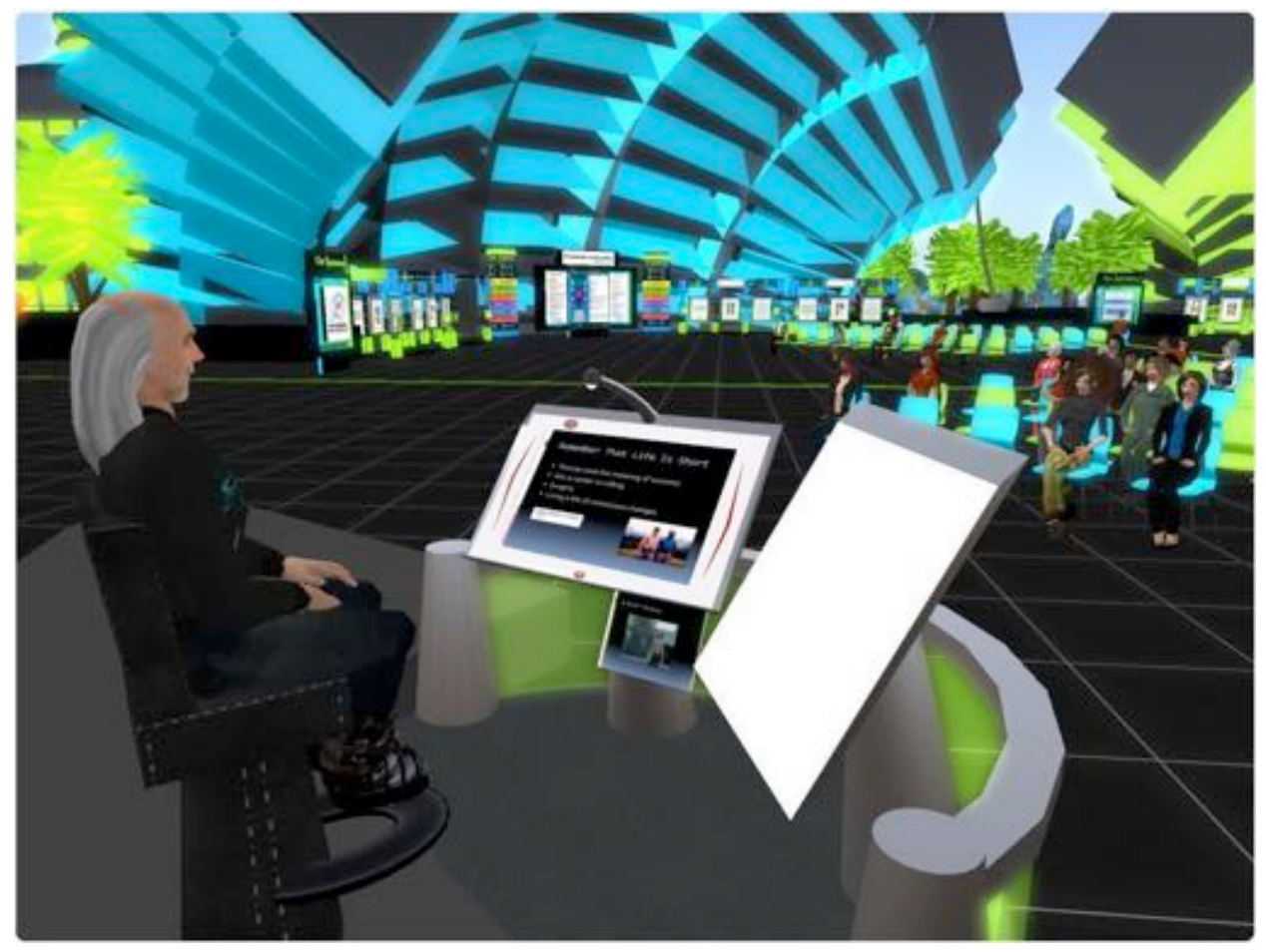

Figure 11. OpenSimulator (http://opensimulator.org). Virtual environment provides a possibility for knowledge transfer and group learning. 


\subsection{Open Wonderland}

Open Wonderland is a Java open-source toolkit for creating collaborative 3D virtual worlds. It was funded by Sun Microsystems since its early development (began as Project Wonderland in 2007.). However, after Sun Microsystems was acquired by Oracle, funding was discontinued (January, 2010.). Open Wonderland continued as an independent community-supported opensource project. At present, all content is made with external tools, such as Blender or Google SketchUp (http://openwonderland.org).

The architecture of the Open Wonderland system is highly modular and fully extensible, so developers can extend its functionality to create entirely new worlds and add new features to existing worlds. Open Wonderland provides a rich set of objects in order to create an environment. Also it supports shared software applications (word processors, web browsers, and document-presentation tools). For example, users can draw on a virtual whiteboard and view documents and presentations. Within virtual worlds, users can communicate through avatars (by means of a headset or microphone and speaker or by the use of a textual chat), and even conduct real business. The idea is to provide a secure world in which organizations can create a virtual presence, and even allow employees to collaborate online and do their real work within a virtual world. In that way, organizations can advance their communication with partners, customers, and employees (Kaplan \& Yankelovich, 2011; Gardner, Ganem-Gutierrez, Scott, Horran, \& Callaghan, 2011).

Open Wonderland is often compared to the Second Life platform. What is important to say is that the Wonderland platform is primarily intended to be tailored and integrated by organizations within their own infrastructures, whereas Second Life is a publicly accessible online service with a very large number of users (Gardner et al., 2011).

A number of examples, regarding the use of the Open Wonderland for educational purposes, is reported (Scheucher, Bailey, Guetl, \& Harward, 2009; Ibanez, Garcia, Galan, Maroto, Morillo, \& Kloos, 2011). Researchers from Athabasca University integrated Open Wonderland with a pedagogical multiagent system named QuizMASter (an educational game for e-learning, that helps students learn through friendly competition) (Blair \& Lin, 2011).

\subsection{Open Cobalt}

Open Cobalt is a free, open source software platform for constructing, accessing, and sharing virtual worlds. It uses the Squeak software environment, which is an open source Smalltalk system. Squeak runs mathematically identical on all machines. Open Cobalt has its technological roots in the Croquet Project (MIT License) - an open source 3D graphical platform (Onyesolu, 2009).

Open Cobalt is designed to enable the deployment of secure, feature-rich virtual worlds that support education, research, and the activities of various virtual organizations. The vision of Open Cobalt is to enable researchers, professors, students, and other users to interact within 3D virtual workspaces. Users and developers can build and share highly capable multi-user virtual workspaces, game-based learning and training environments. They can even create places just to 
meet and interact with other users. One can access Open Cobalt virtual worlds, without any need to access anyone else's servers. Open Cobalt has the ability to leverage peer-to-peer technology as a way of supporting interactions within virtual worlds. It is a major point of difference from commercial multi-user virtual worlds such as Second Life where all in-world interactions are managed by central servers (http://www.opencobalt.org).

\subsection{Unity 3D}

Unity $3 \mathrm{D}$ is a cross-platform game engine. It was developed by Unity Technologies in Denmark. The first version was launched in 2005, at Apple's Worldwide Developers Conference. Unity 3D is a game development ecosystem, a powerful rendering engine fully integrated with a complete set of intuitive tools and rapid workflows to create interactive 3D and 2D content (http://unity3d.com). Unity 3D has an active on-line developer community. They can provide assistance to the new users (Unity 3D offers mobile and web support), and also add new features to the engine at a users request. One of the key features of Unity 3D is its support for modeling physical properties. For example, one can assemble objects, using a variety of joints. Also, various objects can have mass, compliance, collision detection, etc. One of the main differences from the realXtend platform is that Unity 3D comes from the FPS (first person shooting) game arena, whereas realXtend is a multiuser social collaboration environment. Unity 3D is not opensource. Pena Rios, Callaghan, Gardner, \& Alhaddad (2014) presented how Unity 3D can be used to support virtual labs. One of the benefits of using Unity is that it is client based (whereas some other platforms are more server based), thus making it easier to control things in the real space.

The authors are aware of the limitations of the presented review. Limitations concern the absence of an explicit relationship between the list of virtual labs presented in Section 4 and the list of virtual worlds given in this section. We understand that some guidelines for the selection of a virtual world appropriate for a particular lab would be welcomed. However, having in mind that this entire subject is still under research, we decided to provide competent information while considering the formulation of explicit guidelines premature.

\section{Trends and future advances}

This section presents the authors' viewpoint regarding the possible future advances in the field of virtual-worlds-based laboratories for STEM disciplines and in particular for engineering and robotics. By advances in this context we mean both the introduction of technologies that already exist but in a different context (that has not currently been widely applied in Virtual Labs), or the introduction of entirely original concepts.

Our position regarding advances is founded on the proposed requirements and evaluation criteria for virtual laboratories - (C1)-(C4) in section 2. From this review it is possible to identify the weaker aspects of the existing virtual laboratories. These appear to be mainly related to the primary criteria (C2) of dynamics and (C4) virtual spaces. It can be noted from the given examples that these criteria are often met individually, but rarely at the same time. Even when both criteria are fulfilled, there is often still a weakness - for example, the system is generally not flexible enough to allow for new objects to be easily created (the term object means either a single body like a ball, or a complex multi-body system like a robot or a vehicle). Thus, further 
research and development effort is necessary to create advanced virtual worlds based on the dynamics of present real-world objects, and need to be made more flexible with regard to the selection and introduction of new objects.

The foreseen virtual laboratory system will need to be organized into two levels. At the lower level, a library of objects will be created. Each object will be characterized by its shape (3D visual appearance) and its dynamic model. The library will be open for user's inputs. At the higher level, we need to provide a virtual 3D space where the "show will take place". It will need to be made ready to integrate selected objects from the library, and accurately implement their pre-defined visualizations and dynamics. In this way the user can create the dynamic environment for the virtual laboratory. Several users may share the same space, and by introducing objects they can make it their own personalized environment. The space will act as a kind of shell allowing for geometrical and dynamic interaction between objects, based on collision and impact theory. The space may be developed further by using in-built features from an existing 3D Virtual-World platform.

As a further target, we may set a mixed system that will involve a lab consisting of real (authentic, physical) equipment and virtual equipment, "co-present" at the same time. By combining the concepts of virtual reality and mixed reality, some students will be virtually present in the lab (via avatars) while others will be physically present. They will see each other and be able to communicate. Clearly, an innovative new user-interface will be required, such as using mixed-reality glasses. The foundation for this advance has been already set in (Gardner et al., 2011; Callaghan, Gardner, Horran, Scott, Shen, \& Wang, 2008).

Other expected advances and emerging trends lie in the area of alternative input/output devices for virtual worlds (e.g., haptic/force feedback, motion sensing, stereoscopic displays). The advent of consumer-level immersive VR headsets (e.g., Oculus Rift) may also have implications for the field.

\section{Conclusion}

The goal of this paper was to present a critical overview of existing concepts and technologies in the field of fully-software-based virtual laboratories, to identify current trends, and to contribute a solid foundation for future research. In the future our vision is to overcome the barriers that still prevent the wide scale implementation of e- and distance-learning, through the use of virtual worlds, immersive education, and other technologies, and to particularly target STE disciplines (particularly in engineering and robotics).

We have explored the state-of -the-art in virtual laboratories for STE. For the purpose of systematic presentation, the found results are classified into four groups: General Initiatives (2 reviews), Science-Physics (2 reviews), Process Technologies (2 reviews), Engineering - non Robotic (5 reviews), and Engineering - Robotics ( 9 reviews). The relatively greater attention paid to Robotics came out from the found increased interest of researchers for this field. Also, Robotics appeared to be a good representative of complex engineering disciplines. In order to evaluate/compare the virtual laboratories, we have defined the four criteria. The results of comparison are arranged in a table allowing efficient overview. Recognizing the high 
significance of the advanced virtual ambience for creating a successful virtual lab, we explored the state-of-the-art in virtual worlds, and reviewed 6 solutions. Among revealed problems, we point out the introduction of system dynamics where substantial restructure of virtual worlds will be needed. Finally, the paper gives the authors' vision of future research in the topical field. This way, the review paper becomes a comprehensive source of information for those interested in virtual laboratories and e- and distance-learning in general. It can fill in a gap in the existing literature in this fast-growing field, and represent a solid background for future research and development.

The authors are aware that virtual lab systems and simulators are often currently only used as an initial step in a student's engineering education and training, followed by more in-depth handson experience with real authentic equipment. We may agree with this viewpoint (based on the current state of the art) but also recognize that the continued progress in computer graphics, virtual reality, and virtual worlds technologies can provide the opportunity to rapidly enlarge the use of virtual laboratory based systems applications, and can eventually reduce the need for real world laboratories altogether.

Last but not the least, we have to say that, besides the technical issues addressed in this paper, the implementation of immersive education, distance learning, and virtual worlds open up significant questions in the field of pedagogy and the design of effective learning "experiences". However, regardless of the fact that technology and pedagogy drive each other, the pedagogy issues are out of the scope of this paper.

\section{References}

Abdulwahed, M., \& Nagy, Z. (2013). Developing the TriLab, a triple access mode (hands-on, virtual, remote) laboratory, of a process control rig using LabVIEW and Joomla. Computers Applications in Engineering Education (John Wiley \& Sons), 21(4), 614-626.

Allison, C., Campbell, A., Davies, C. J., Dow, L., Kennedy, S., McCaffery, J., Miller, A., Oliver, I., \& Perera, I. (2012). Growing the Use of Virtual Worlds in Education: an OpenSim Perspective. In Proceedings of the 2nd European Immersive Education Summit, Paris, France, 1-13.

Andreas, K., Thrasyvoulos, T., Stavros, D., Andreas, P. (2010). Collaborative Learning in OpenSim by Utilizing Sloodle. In Proceedings of the 6th Advanced International Conference on Telecommunications (AICT 2010), Barcelona, Spain, 90-95.

Axup, J., Thomas, A., Waldman, A., Faulkner, S., Odman-Govender, C., St.Leger, J., Polka, J., Gregg, M., \& Johnson, B. D. (2014). The World of Making. IEEE Computer, 47 (12), 24-40.

Aziz, E.-S. S., Esche, S. K., \& Chassapis, C. (2009). Content-rich interactive online laboratory systems. Computers Applications in Engineering Education (John Wiley \& Sons), 17(1), 61-79.

Aziz, E.-S. S., Chang, Y., Esche, S. K., \& Chassapis, C. (2014). A multi-user virtual laboratory environment for gear train design. Computers Applications in Engineering Education (John Wiley \& Sons), 22(4), 788-802. 
Babich, A., \& Mavrommatis, K. T. (2009). Teaching of Complex Technological Processes Using Simulations. International Journal of Engineering Education, 25(2), 209-220.

Barkand, J., \& Kush, J. (2009). GEARS a 3D Virtual Learning Environment Used in Online Secondary Schools. In Proceedings of the 4th International Conference on e-Learning (ICEL 2009), Toronto, Canada, 48-51.

Blair, J., \& Lin, F. (2011). An Approach for Integrating 3D Virtual Worlds with Multiagent Systems. In Proceedings of the 2011 IEEE Workshops of International Conference on Advanced Information Networking and Applications (WAINA), Biopolis, Singapore, 580-585.

Boulos, M. N. K., Hetherington, L., \& Wheeler, S. (2007). Second Life: an overview of the potential od 3 -D virtual worlds in medical and health education. Health Information and Libraries Journal (John Wiley \& Sons), 24(4), 233-245.

Callaghan, V., Gardner, M., Horran, B., Scott, J., Shen, L., \& Wang, M. (2008). A Mixed Reality Teaching and Learning Environment. Lecture Notes in Computer Science (including subseries Lecture Notes in Artifical Intelligence and Lecture Notes in Bioinformatics), 5169, 54-65.

Carpin, S., Lewis, M., Wang, J., Balakirsky, S., \& Scrapper, C. (2007). USARSim: a robot simulator for research and education. In Proceedings of the 2007 IEEE International Conference on Robotics and Automation (ICRA '07), Rome, Italy, 1400-1405.

Davies, M., \& Callaghan, V. (2010). iWorlds: Building Mixed Reality Intelligent Environments using Customisable 3D Virtual Worlds. In Proceedings of the IEEE Sixth International Conference on Intelligent Environments, Kuala Lumpur, Malaysia, 311-314.

de Jong, T., Sotiriou, S., \& Gillet, D. (2014). Innovations in STEM Education: the Go-Lab federation of online labs. Smart Learning Environments, 1:3, 1-16.

Dieterle, E., \& Clarke, J. (2009). Multi-user Virtual Environments for Teaching and Learning. In M. Pagani (Ed.), Encyclopedia of Multimedia Technology and Networking (pp. 1033-1041). Hershey PA: IGI Global.

Duncan, I., Miller, A., \& Jiang, S. (2012). A taxonomy of virtual worlds usage in education. British Journal of Educational Technology, 43(6), 949-964.

Freund, E., \& Pensky, D. H. (2002). COSIMIR Factory: extending the use of manufacturing simulations. In Proceedings of the 2002 IEEE International Conference on Robotics and Automation (ICRA '02), Washington DC, USA, 2805-2810.

Gardner, M., Ganem-Gutierrez, A., Scott, J., Horran, B., \& Callaghan, V. (2011). Immersive Education Spaces Using Open Wonderland: From Pedagogy Through to Practice. In G. Vincenti, \& J. Braman, Multi-User Environments for the Classroom: Practical Approaches to Teaching in Virtual Worlds (pp. 190-205), Hershey PA: IGI Global.

Govaerts, S., Cao, Y., Vozniuk, A., Holzer, A. C., Garbi Zutin, D., San Cristóbal Ruiz, E., Bollen, L., Manske, S., Faltin, N., \& Salzmann, C. (2013). Towards an Online Lab Portal for Inquiry-based STEM Learning at School. In Advances in Web-Based Learning - ICWL 2013 (Proceedings of the 12th International Conference on Web-based Learning), Kenting, Taiwan, 244-253. 
Hashemipour, M., Manesh, H. F., \& Bal, M. (2011). A Modular Virtual Reality System for Engineering Laboratory Education. Computers Applications in Engineering Education (John Wiley \& Sons), 19(2), 305-314.

Honey, M., \& Kanter, D. E. (2013). Design, Make, Play: Growing the Next Generation of STEM Innovators. New York: Routledge (an imprint of the Taylor \& Francis).

Huang, H.-M., Rauch, U., \& Liaw, S.-S. (2010). Investigating learner's attitudes toward virtual reality environments: Based on a constructivist approach. Computers \& Education (Elsevier), 55(3), 1171-1182.

Hut, P. (2007). Virtual Laboratories and Virtual Worlds. In Proceedings of the IAU Symposium Dynamical Evolution of Dense Stellar Systems, Capri, Italy, 447-456.

Ibanez, M. B., Garcia, J. J., Galan, S., Maroto, D., Morillo, D., \& Kloos, C. D. (2011). Design and Implementation of a 3D Multi-User Virtual World for Language Learning. Educational Technology and Society, 14(4), 2-10.

Ibanez, M.-B., Di-Serio, A., \& Delgado-Kloos, C. (2014). Gamification for Engaging Computer Science Students in Learning Activities: A Case Study. IEEE Transactions on Learning Technologies, 7(3), 291301.

Jara, C., Candelas, F., Puente, S., \& Torres, F. (2011). Hands on Experiences of Undergraduate Students in Automatics and Robotics Using a Virtual and Remote Laboratory. Computers and Education (Elsevier), 57(4), 2451-2461.

Jaramillo-Botero, A., Matta-Gómez, A., Correa-Caicedo, J. F., \& Perea-Castro, W. (2006). ROBOtics Modeling and Simulation Platform. IEEE Robotics \& Automation Magazine, 13(4), 62-73.

Jeschke, S., Hauck, E., Pfeiffer, O., \& Richter, T. (2009). Robotics as Demonstrator Discipline for Networked Virtual and Remote Laboratories. In Proceedings of the IEEE Workshop on Advanced Robotics and its Social Impacts (ARSO 2009), Tokyo, Japan, 109-113.

Kaluz, M., Cirka, L., \& Fikar, M. (2011). Virtual laboratory of process control. In Proceedings of the 18th International Conference on Process Control, Tatranska Lomnica, Slovakia, 348-351.

Kaplan, A., \& Haenlein, M. (2010). Users of the world, unite! The challenges and opportunities of social media. Business Horizons (Elsevier), 53(1), 59-68.

Kaplan, J. \& Yankelovich, N. (2011). Open Wonderland: An Extensible Virtual World Architecture. IEEE Internet Computing, 15(5), 38-45.

Ketelhut, D. J. (2007). The Impact of Student Self-efficacy on Scientific Inquiry Skills: An Exploratory Investigation in River City, a Multi-user Virtual Environment. Journal of Science Education and Technology, 16(1), 99-111.

Koretsky, M., Amatore, D., Barnes, C., \& Kimura, S. (2008). Enhancement of Student Learning in Experimental Design Using a Virtual Laboratory. IEEE Transactions on Education, 51(1), 76-85.

Mattila, P., Krajnak, J., Arhippainen, L., \& Brauer, S. (2012). Education in 3D Virtual Learning Environment - Case Virtual-Mustiala. In Proceedings of the 2nd European Immersive Education Summit, Paris, France, 134-145. 
Noguez, J., \& Enrique Sucar, L. (2006). Intelligent Virtual Laboratory and Project Oriented Learning for Teaching Mobile Robotics. International Journal of Engineering Education, 22(4), 743-757.

Onyesolu, M. O. (2009). Virtual Reality Laboratories: An Ideal Solution to the Problems Facing Laboratory Setup and Management. In Proceedings of the World Congress on Engineering and Computer Science (WCECS 2009), San Francisco, USA, 291-295.

Pan, Z., Cheok, A. D., Yang, H., Zhu, J., \& Shi, J. (2006). Virtual reality and mixed reality for virtual learning environments. Computers \& Graphics (Elsevier), 30(1), 20-28.

Pena-Rios, A. P., Callaghan, V., Gardner, M., \& Alhaddad, M. J. (2014). Interactions within Distributed Mixed Reality Collaborative Environments. In Proceedings of the 2014 International Conference on Intelligent Environments (IE), Shanghai, China, 382-383.

Potkonjak, V., Vukobratović, M., Jovanović, K., \& Medenica, M. (2010). Virtual Mechatronic/Robotic Laboratory - A Step Further in Distance Learning. Computers \& Education (Elsevier), 55(2), 465-475.

Potkonjak, V., Jovanovic, K., Petrovic, V. M., Holland, O., \& Uhomoibhi, J. (2013a). Virtual Ambient for E-Learning in Engineering Sciences. In Proceedings of the Conference of the International Journal of Arts and Sciences, 6(1), Valletta, Malta, 7-14.

Potkonjak, V., Jovanovic, K., Holland, O., \& Uhomoibhi, J. (2013b). Distance learning and skill acquisition in engineering sciences - present state and prospects. Multicultural Education and Technology Journal, 7(1), 64-88.

Richter, T., Boehringer, D., \& Jeschke, S. (2009). LiLa: A European Project on Networked Experiments. In Proceedings of the 6th International Conference on Remote Engineering and Virtual Instrumentation (REV 2009), Bridgeport, CT, USA, 41-46.

Santos, F. R., Guetl, C., Bailey, P., \& Harward V. J. (2010). Dynamic Virtual Environment for Multiple Physics Experiments in Higher Education. In Proceedings of the 2010 IEEE Engineering Education Conference (EDUCON), Madrid, Spain, 731-736.

Sapena, O., Onaindia, E., Mellado, M., Correcher, C., \& Vendrell, E. (2004). Reactive Planning Simulation in Dynamic Environments with VirtualRobot. Lecture Notes in Artificial Intelligence (Subseries of Lecture Notes in Computer Science), 3029, 699-707.

Scheucher, B., Bailey, P. H., Guetl, C. \& Harward, J. (2009). Collaborative Virtual 3D Environment for Internet-Accessible Physics Experiments. International Journal of Online Engineering (Special Issue REV2009), 5, 65-71.

Sheri, Y., Legaspi, E. G., Erenas, C., Kessler, B., Gentry, E., \& Estrada, R. (2014). The Future of Making. IEEE Computer, 47(12), 56-63.

Tanyildizi, E., \& Orhan, A. (2009). A virtual electric machine laboratory for synchronous machine application. Computers Applications in Engineering Education (John Wiley \& Sons), 17(2), 187-195.

Tlaczala, W., Zaremba, M., Zagorski, A., \& Gorghiu, G. (2009). Virtual Physics Laboratory for Distance Learning Developed in the Frame of the VccSSe European Project. In Proceedings of the Fifth International Conference on Multimedia \& ICT's in Education, Lisbon, Portugal, 467-471. 
Torres, F., Candelas, F., Puente, S., Pomares, J., Gil, P., \& Ortiz, F. (2006). Experiences with Virtual Environment and Remote Laboratory for Teaching and Learning Robotics at the University of Alicante. International Journal of Engineering Education, 22(4), 766-776.

Villar-Zafra, A., Zarza-Sánchez, S., Lázaro-Villa, J. A., \& Fernández-Cantí, R. M. (2012). Multiplatform Virtual Laboratory for Engineering Education. In Proceedings of the 9th International Conference on Remote Engineering and Virtual Instrumentation (REV), Bilbao, Spain, 1-6.

Voss, G. B., Nunes, F. B., Muhlbeier, A. R. K., \& Medina, R. D. (2013). Context-Aware Virtual Laboratory for Teaching Computer Networks: A proposal in the 3D OpenSim environment. In Proceedings of the 15th Symposium on Virtual and Augmented Reality (SVR 2013), Cuiaba, Mato Grosso, Brazil, 252-255.

Vukobratović, M., \& Potkonjak, V. (1982). Dynamics of Manipulation Robots. Berlin: Springer-Verlag.

Vukobratović, M., \& Potkonjak, V. (1985). Applied Dynamics and CAD of Manipulation Robots. Berlin: Springer-Verlag.

Vukobratović, M., Potkonjak, V., \& Matijević, V. (2003). Dynamics of Robots with Contact Tasks, Dordrecht: Kluwer Academic Publishers.

Warburton, S. (2009). Second Life in higher education: Assessing the potential for and the barriers to deploying virtual worlds in learning and teaching. British Journal of Educational Technology, 40(3), 414426.

Wiecha, J., Heyden, R., Sternthai, E. \& Merialdi, M. (2010). Learning in a Virtual World: Experience With Using Second Life for Medical Education. Journal of Medical Internet Research, 12(1), e1. 